\title{
Polyacrylates Derived from Bio-Based Ethyl Lactate Solvent via SET-LRP
}

\author{
Nabil Bensabeh,${ }^{\dagger}$ Adrian Moreno,${ }^{\dagger}$ Adrià Roig, ${ }^{\dagger}$ Olivia Monaghan, ${ }^{\dagger}$ Juan C. Ronda,${ }^{\dagger}$ Virginia Cádiz,${ }^{\dagger}$ \\ Marina Galià, ${ }^{\dagger}$ Steven M. Howdle, ${ }^{\ddagger}$ Gerard Lligadas, ${ }^{* \dagger}$ and Virgil Percec* ${ }^{\star \S}$
}

${ }^{\dagger}$ Laboratory of Sustainable Polymers, Department of Analytical Chemistry and Organic Chemistry, University Rovira i Virgili, Tarragona, Spain

${ }^{\ddagger}$ School of Chemistry, University of Nottingham, University Park Nottingham NG7 2RD, Nottingham, UK

${ }^{\S}$ Roy \& Diana Vagelos Laboratories, Department of Chemistry, University of Pennsylvania, Philadelphia, Pennsylvania 19104-6323, United States

\begin{abstract}
:
The precise synthesis of polymers derived from alkyl lactate ester acrylates is reported for the first time. Kinetic experiments were conducted to demonstrate that $\mathrm{Cu}(0)$ wire-catalyzed single electron transferliving radical polymerization (SET-LRP) in alcohols at $25^{\circ} \mathrm{C}$ provides a green methodology for the LRP of this forgotten class of bio-based monomers. The acrylic derivative of ethyl lactate (EL) solvent and homologous structures with methyl and $n$-butyl ester were polymerized with excellent control over molecular weight, molecular weight distribution, and chain end functionality. Kinetics plots in conventional alcohols such as ethanol and methanol were first order in monomer with molecular weight increasing linearly with conversion. However, aqueous EL mixtures were found to be more suitable than pure EL to mediate the SET-LRP process. The near quantitative monomer conversion and high bromine chain-end functionality, demonstrated by MALDI-TOF analysis, further allowed the preparation of innovative bio-based block copolymers containing rubbery poly(ELA) sequences. For instance, poly(ELA-b-poly(glycerol acrylate) block copolymer self-assembled in water to form stable micelles with chiral lactic acid-derived block forming micellar core as confirmed by pyrene-probe-based fluorescence technique. Dynamic light scattering (DLS) and transmission electron microscopy (TEM) measurements revealed nanosize spherical morphology for these bio-based aggregates.
\end{abstract}

Keywords: renewable, low $\mathrm{T}_{\mathrm{g}}$, SET-LRP, ethyl lactate, amphiphilic 


\section{INTRODUCTION}

Naturally occurring lactic acid (2-hydroxypropionic acid) was first isolated from sour milk by the Swedish chemist Scheele in 1780. Later on, this hydroxycarboxylic acid progressively became an industrial important product due to its versatile functional properties as a flavor agent, $\mathrm{pH}$ regulator, and preservative. ${ }^{1}$ Currently, about $90 \%$ of the enantiomerically pure lactic acid is produced by the fermentation of refined carbohydrates with appropriate microorganisms. ${ }^{2}$ However, more convenient bioprocessing technologies based on lignocellulosic raw materials are already consolidated. ${ }^{3}$ In recent years, the derivation of polymeric materials from sustainable and annually renewable resources, such as vegetable oils, sugars, terpenes, polysaccharides, rosins and lignin, among others, has attracted increasing interest due to dwindling of fossil oil resources and environmental impact of petroleum manufacturing. ${ }^{4,5}$ To this end, lactic acid has shown particular promise in production of poly(lactic acid) (PLA), either by its own polycondensation or ring-opening polymerization (ROP) of its cyclic dimer lactide. ${ }^{6,78}$

The preparation of well-defined $\mathrm{ABA}$ thermoplastic elastomers illustrates an example on how recent advances in living radical polymerization has started a new era in the preparation of biomass-derived polymers with advanced properties and functions. ${ }^{9,10,11,12}$ In this regard, single electron transfer living radical polymerization (SET-LRP) has gained great popularity as a facile tool for precision macromolecular engineering. ${ }^{13,14,15,16,17,18,19}$ For example, when conducted in reaction media that facilitates disproportionation of $\mathrm{Cu}(\mathrm{I}) \mathrm{Br}$ into $\mathrm{Cu}(0)$ and $\mathrm{Cu}(\mathrm{II}) \mathrm{Br}_{2}{ }^{20,21,22}$ this method enables the synthesis of vinylic polymers with nearly $100 \%$ chain end functionality at complete conversion. ${ }^{23,24,25,26}$ This has been demonstrated to be feasible even in "programmed" biphasic SET-LRP systems (i.e. aqueous-organic solvent mixtures based on both disproportionating $27,28,29$ and non-disproportionating organic

solvents). ${ }^{30,31,32,33}$ Consequently, benefiting from this and other inherent attributes (e.g. facile setup, ambient temperature, oxygen tolerance, compatibility with water and biological media), SET-LRP is an 
appealing platform to create well-defined bio-based polymers and limitless number of block copolymers therefrom. The preparation of sequence controlled multi-block glycopolymers ${ }^{34,35}$ and the controlled grafting of natural polysaccharides ${ }^{36,37}$ exemplifies successful efforts. Also, aside from the excellent synergy of SET-LRP with water $\left(\mathrm{H}_{2} \mathrm{O}\right)$ and conventional alcohols, ${ }^{17,19}$ it is compatible with other ecofriendly solvents such as polyethylene glycols, ${ }^{38}$ ionic liquids ${ }^{13,39}$ and $\mathrm{N}, \mathrm{N}$-dimethyl lactamide (DML) ${ }^{40}$ without detrimentally affecting polymerization. More recently, it was also demonstrated that ethyl lactate (EL) possesses interesting features related to SET-LRP, ${ }^{41}$ thus expanding the myriad of academic/industrial applications found for this promising bio-sourced solvent. ${ }^{42,43,44,45}$

Acrylic derivatives of alkyl lactate esters are a forgotten class of sustainable monomers in polymer synthesis which complement the classic alkyl acrylates palette by increasing the density of polar and hydrolysable ester groups per repeat unit. In addition, well-defined poly(alkyl lactate acrylate)s may be important candidates for applications in chiral recognition and enantioselective catalysis because alkyl lactates are chiral synthons. To the best of our knowledge, there is no report on the LRP of such bio-based monomers. Surprisingly, even their free radical polymerization received limited attention. ${ }^{46,47,48}$ Herein, our attention was focused on ethyl lactate acrylate (ELA, Scheme 1) and investigated $\mathrm{Cu}(0)$ wire-catalyzed SET-LRP for the synthesis of well-defined poly(ELA) under mild and environmentally friendly conditions. This method also enables control over the polymerization of homologous monomers with methyl and $n$-butyl ester groups (Scheme 1). Further, the block copolymerization of poly(ELA) was accomplished with other monomers derived from biomass feedstock resulting in well-defined block copolymers including chiral alkyl lactate acrylate sequences.

\section{EXPERIMENTAL SECTION}


Materials. The following chemicals were purchased from Sigma-Aldrich and were used as received: methyl 2-bromopropionate (MBP, 98\%), ethyl $\alpha$-bromoisobutyrate (EBiB, 98\%), $\alpha$-bromoisobutyryle bromide (98\%), acryloyl chloride $(\geq 97 \%), \quad$ dowex $^{\circledR} \quad 50 \mathrm{WX} 4$ hydrogen form, tris[2(dimethylamino)ethyl]amine ( $\left.\mathrm{Me}_{6}-\mathrm{TREN}, \quad 97 \%\right), \quad$ copper(II) bromide $\quad\left(\quad \mathrm{Cu}(\mathrm{II}) \mathrm{Br}_{2}, \quad 99 \%\right)$, propylphosphonic anhydride solution $\left(\mathrm{T}^{\mathrm{P}} \mathrm{P}^{\circledR}, \geq 50\right.$ wt. \% in ethyl acetate), pyrene ( $\left.\geq 99 \%\right)$, hydrazine hydrate (60\% hydrazine), DL-1,2-isopropylideneglycerol ( $\geq 99 \%$, 2-methyltetrahydrofuran (2-MeTHF, $\geq 99 \%$ ), thiophenol ( $\mathrm{PhSH}, \geq 99 \%$ ), dimethylsulfoxide (DMSO, $\geq 99.7 \%$ ), trans-2-[3-(4-tert-butylphenyl)2-methyl-2-propenylidene]malononitrile ( $\geq 98 \%)$ and potassium trifluoroacetate (KTFA, 98\%). 1,1,1Tris(hydroxymethyl)ethane was received from Alfa Aesar. Acrylic acid (stabilised with hydroquinone monomethyl ether, for synthesis), 2,2,2-trifluoroethanol ( $\geq 99 \%$ ) and HPLC grade acetonitrile were obtained from Merck. HPLC grade methanol (MeOH) and ethanol (96\%) were purchased from Scharlab and VWR Chemicals, respectively. Acetone (synthesis grade) was also purchased from Scharlab. The radical inhibitor of methyl acrylate (MA, 99\%, Sigma Aldrich) was removed by passing the monomer through a short column of basic $\mathrm{Al}_{2} \mathrm{O}_{3}$ prior to use. Deuterated chloroform $\left(\mathrm{CDCl}_{3}\right)$ was purchased from Eurisotop. Ethyl lactate (EL, natural, $\geq 98 \%$ ), methyl L-lactate (ML, 98\%) and butyl L-lactate (BL, $\geq 99 \%$ ) were purchased from Sigma-Aldrich and distilled prior to use. Triethylamine (TEA, $\geq 99 \%$, Merck) and dichloromethane (DCM, reagent grade, Scharlab) were distilled from $\mathrm{CaH}_{2}$. Propan-2-ol (2-PrOH, $>97.7 \%$ ) was passed through a short column of basic $\mathrm{Al}_{2} \mathrm{O}_{3}$ and freshly distilled before to use. Ethylene glycol ( $\geq 99 \%$, Sigma-Aldrich) was dried by azeotropic distillation before to use and stored under inert atmosphere. Ethylene bis(2-bromoisobutyrate) (bisEBiB) ${ }^{49}$ and ethane-1,2-diyl bis(2-bromo-2methylpropanoate) $\left((\mathrm{OH})_{2} \mathrm{EBiB}\right)^{50}$ initiators and both solketal ${ }^{51}$ and $\alpha$-pinene ${ }^{52}$ acrylates (SA and $\alpha \mathrm{PA}$, respectively) were prepared according to literature procedures. Copper(0) wire $99.9 \%$ pure of 20 gauge 
diameter, received from Creating Unkamen, was activated using hydrazine following a procedure developed in our laboratory. ${ }^{53}$

Methods. Proton ( ${ }^{1} \mathrm{H}$ NMR) and carbon $\left({ }^{13} \mathrm{C}\right.$ NMR $)$ nuclear magnetic resonance spectra were recorded on a $400 \mathrm{MHz}$ (for ${ }^{1} \mathrm{H}$ ) and $100.6 \mathrm{MHz}$ (for ${ }^{13} \mathrm{C}$ ) Varian VNMR-S400 NMR instrument at $25{ }^{\circ} \mathrm{C}$ in $\mathrm{CDCl}_{3}$. All chemical shifts are quoted on the $\delta$ scale in ppm using the residual solvent as internal standard $\left({ }^{1} \mathrm{H}\right.$ NMR: $\mathrm{CDCl}_{3}=7.26$ and ${ }^{13} \mathrm{C}$ NMR: $\mathrm{CDCl}_{3}=77.16$ ). Infrared (IR) spectra were recorded on a FTIR680PLUS spectrophotometer with a resolution of $4 \mathrm{~cm}^{-1}$ in the transmittance mode. An attenuated total reflection (ATR) devise with thermal control and a diamond crystal (Golden Gate heated single-reflection diamond ATR, Specac-Teknokroma) was used. Absorption maxima $\left(v_{\max }\right)$ are reported in wavenumbers $\left(\mathrm{cm}^{-1}\right)$. Fluorescence spectra were obtained on an RF-5301 PC Shimadzu fluorescence spectrometer with a RFPC software with emission using excitation slit widths of $5 \mathrm{~nm}$. Supercritical fluidic chromatography (SFC) analysis was performed on a supercritical $\mathrm{CO}_{2}$ chromatograph UPC2 from Waters equipped with Chiralpak IC (100x4.6 mm, $3 \mu \mathrm{m})$ column coupled with a DAD detector. $\mathrm{CO}_{2} / 2-\mathrm{PrOH}(98: 2)$ was used as eluent at a flow rate of $3.0 \mathrm{~mL} / \mathrm{min}$ with the control ABPR pressure set at $1500 \mathrm{psi}$. ESI MS analysis were run on a chromatographic system Agilent G3250AA liquid chromatography coupled to 6210 time of flight (TOF) mass spectrometer from Agilent Technologies with an electrospray ionization (ESI) interface. Nominal and exact $\mathrm{m} / \mathrm{z}$ values are reported in Daltons $(\mathrm{Da})$. Optical rotations measurements were conducted on a Perkin-Elmer $241 \mathrm{MC}$ polarimeter with a path length of $10 \mathrm{~cm}$ and are reported with implied units of $10^{-1} \mathrm{deg} \mathrm{cm}^{2} \mathrm{~g}^{-1}$. Molecular weight analysis was performed via gel permeation chromatography (GPC) using an Agilent 1200 series system equipped with three serial columns (PLgel 3 $\mu \mathrm{m}$ MIXED-E, PLgel $5 \mu \mathrm{m}$ MIXED-D and PLgel $20 \mu \mathrm{m}$ from Polymer Laboratories) and an Agilent 1100 series refractive-index detector. THF (Panreac, HPLC grade) was used as eluent at a flow rate of 1.0 $\mathrm{mL} / \mathrm{min}$. The calibration curves for GPC analysis were obtained with poly(methyl methacrylate) (PMMA) 
standards purchased from PSS Polymer Standards Service GmbH. The molecular weights were calculated using the universal calibration principle and Mark-Houwink parameters. MALDI-TOF analysis was performed on a Voyager DE (Applied Biosystems) instrument with a 337-nm nitrogen laser (3-ns pulse width). For all polymers, the accelerating potential was $25 \mathrm{kV}$, the grid voltage was $93.5 \%$, the laser power was 1700 units, and a positive ionization mode was used. The analysis was performed with trans-2-[3-(4tert-butylphenyl)-2-methyl-2-propenylidene]malononitrile as matrix. THF solutions of the matrix (30 $\mathrm{mg} / \mathrm{mL}), \mathrm{KTFA}$ as cationization agent $(10 \mathrm{mg} / \mathrm{mL})$, and polymer $(10 \mathrm{mg} / \mathrm{mL})$ were prepared separately. The solution for MALDI-TOF analysis was obtained by mixing the matrix, polymer and salt solutions in a 9/1/1 volumetric ratio. Then $1 \mu \mathrm{L}$ portions of the mixture were deposited onto three wells of a sample plate and dried in air at room temperature before being subjected to MALDI-TOF analysis. Differential scanning calorimetry (DSC) measurements were carried out on a Mettler DSC3+ instrument using $\mathrm{N}_{2}$ as a purge gas $(50 \mathrm{~mL} / \mathrm{min})$ at scanning rate $20{ }^{\circ} \mathrm{C} / \mathrm{min}$ in the -80 to $150{ }^{\circ} \mathrm{C}$ temperature range. Calibration was made using an indium standard (heat flow calibration) and an indium-lead-zinc standard (temperature calibration). Thermal stability studies were carried out on a Mettler TGA2 /LF/1100 with $\mathrm{N}_{2}$ as a purge gas at flow rate of $50 \mathrm{~mL} / \mathrm{min}$. The studies were performed in the $30-600{ }^{\circ} \mathrm{C}$ temperature range at a heating rate of $10{ }^{\circ} \mathrm{C} / \mathrm{min}$. Transmission electron microscopy (TEM) was performed using a JEOL JEM-1011 TEM microscope. Before the measurement, a drop of solution was placed on a copper grid which was allowed to dry at room temperature. Dynamic light scattering (DLS) measurements were carried out at room temperature using Zetasizer Nano ZS (Model ZEN3500) from Malvern Instruments equipped with a He-Ne laser. Chiral polymers were characterized on a Chirascan circular dichroism spectrometer from Applied Photophysics. The contactangle of deionised water against polymer surfaces was measured by the water drop method $(3 \mu \mathrm{L})$ at $25^{\circ} \mathrm{C}$, using the OCA15EC contact angle setup (Neurtek Instruments). 
Synthesis of Alkyl Lactate Acrylate Monomers. This procedure is generic for all the alkyl lactate monomers synthesized herein. The synthesis of ELA is described. Ethyl lactate (20.0 g, $0.17 \mathrm{~mol})$ and anhydrous TEA (26.5 g, $0.26 \mathrm{~mol})$ were dissolved in dry DCM $(50 \mathrm{~mL})$ under a positive flow of argon. The solution was stirred for $30 \mathrm{~min}$ at $0-5^{\circ} \mathrm{C}$ before adding dropwise acryloyl chloride (18.4 g, $\left.0.20 \mathrm{~mol}\right)$ dissolved in dry DCM $(50 \mathrm{~mL})$. The reaction was allowed to proceed for $24 \mathrm{~h}$ at room temperature. The mixture was then filtered and then washed with $\mathrm{HCl} 1 \mathrm{M}(150 \mathrm{~mL})$ and saturated $\mathrm{NaHCO}_{3}$ solution $(150$ $\mathrm{mL}$ ). The organic layer was rinsed with brine solution and dried over anhydrous $\mathrm{MgSO}_{4}$. The final residue was purified by vacuum distillation in the presence of 5 (w/w \%) of hydroquinone to afford ELA (20.4 g, $70 \%)$ as a colorless liquid. $[\alpha]_{\mathrm{D}}{ }^{20}-53.9(1.0 \mathrm{mg} / \mathrm{mL}, \mathrm{MeCN}) .{ }^{1} \mathrm{H} \mathrm{NMR}\left(400 \mathrm{MHz}, \mathrm{CDCl}_{3}, \delta\right): 6.48(\mathrm{dd}$, 1H), $6.19(\mathrm{dd}, 1 \mathrm{H}), 5.89(\mathrm{dd}, 1 \mathrm{H}), 5.15(\mathrm{q}, 1 \mathrm{H}), 4.21(\mathrm{q}, 2 \mathrm{H}), 1.53(\mathrm{~d}, 3 \mathrm{H}), 1.28(\mathrm{t}, 3 \mathrm{H}) ;{ }^{13} \mathrm{C}$ NMR $(100.6$ $\left.\mathrm{MHz}, \mathrm{CDCl}_{3}, \delta\right): 170.72,165.43,131.86,127.78,68.85,61.42,17.01,14.14$. FTIR-ATR (neat, $v_{\max }$ ): 2989, 1748, 1726, 1637, 1406, 1179, 809. HRMS $\left(\right.$ TOF ES $^{+}$) $m / z:[\mathrm{M}+\mathrm{H}]^{+}$calcd for $\mathrm{C}_{8} \mathrm{H}_{13} \mathrm{O}_{4}{ }^{+}, 173.0808$, found, 173.0809 .

Methyl lactate acrylate (MLA): ${ }^{1} \mathrm{H}$ NMR $\left(400 \mathrm{MHz}, \mathrm{CDCl}_{3}, \delta\right): 6.48$ (dd, 1H), 6.19 (dd, 1H), 5.91 (dd, 1H), 5.17 (q, 1H), $3.76(\mathrm{~s}, 3 \mathrm{H}), 1.54(\mathrm{~d}, 3 \mathrm{H}) ;{ }^{13} \mathrm{C} \mathrm{NMR}\left(100.6 \mathrm{MHz}, \mathrm{CDCl}_{3}, \delta\right): 171.00,165.18,131.78$, 127.57, 68.55, 52.20, 16.84. FTIR-ATR (neat, $v_{\max }$ ): 2995, 2956, 1749, 1725, 1637, 1406, 1178, 808. HRMS (TOF ES ${ }^{+}$) $m / z:[\mathrm{M}+\mathrm{H}]^{+}$calcd for $\mathrm{C}_{7} \mathrm{H}_{11} \mathrm{O}_{4}{ }^{+}, 159.0652$, found, 159.0656 .

n-Butyl lactate acrylate (BLA): ${ }^{1} \mathrm{H}$ NMR $\left(400 \mathrm{MHz}, \mathrm{CDCl}_{3}, \delta\right): 6.48$ (dd, 1H), 6.19 (dd, 1H), 5.90 (dd, 1H), $5.16(\mathrm{q}, 1 \mathrm{H}), 4.16(\mathrm{~m}, 2 \mathrm{H}), 1.63(\mathrm{~m}, 2 \mathrm{H}), 1.53(\mathrm{~d}, 3 \mathrm{H}), 1.38(\mathrm{~m}, 2 \mathrm{H}), 0.93(\mathrm{t}, 3 \mathrm{H}) ;{ }^{13} \mathrm{C}$ NMR $(100.6$ $\left.\mathrm{MHz}, \mathrm{CDCl}_{3}, \delta\right): 170.72,165.34,131.74,127.71,68.78,65.13,30.51,18.99,16.96,13.62$. FTIR-ATR (neat, $\left.v_{\max }\right): 2961,2875,1750,1723,1637,1406,1179,807 . \mathrm{HRMS}\left(\mathrm{TOF} \mathrm{ES}^{+}\right) \mathrm{m} / z:[\mathrm{M}+\mathrm{H}]^{+}$calcd for $\mathrm{C}_{10} \mathrm{H}_{17} \mathrm{O}_{4}^{+}, 201.1121$, found, 201.1119 . 
Synthesis of ELA with the Aid of Acrylic Acid. Acrylic acid (0.70 mL, $10.18 \mathrm{mmol})$, TEA (3.65 mL, 26.19 $\mathrm{mmol})$ and $\mathrm{T}^{\mathrm{P}} \mathrm{P}^{\circledR}(6.73 \mathrm{~g}, 10.58 \mathrm{mmol})$ were added to a solution of ethyl lactate $(1 \mathrm{~mL}, 8.72 \mathrm{mmol})$ in MeTHF (50 mL). The mixture was stirred for $48 \mathrm{~h}$ at room temperature. The reaction was monitored by ${ }^{1} \mathrm{H}$ NMR. After $48 \mathrm{~h}$, the reaction was diluted with water $(30 \mathrm{~mL})$ and the aqueous phase was extracted with diethyl ether $(3 \times 30 \mathrm{~mL})$. The combined organic layers were rinsed with aqueous $\mathrm{HCl} 1 \mathrm{M}(30 \mathrm{~mL})$, saturated aqueous solution of $\mathrm{NaHCO}_{3}(30 \mathrm{~mL})$, brine $(20 \mathrm{~mL})$ and finally dried with $\mathrm{MgSO}_{4}$. The resulting solution was concentrated under reduced pressure, and the residue was purified by column chromatography (9:1 hexanes/ethyl acetate) to afford ELA (0.9 g, 60\%) as a colorless liquid.

$\mathrm{Cu}(0)$-Catalyzed SET-LRP of Alkyl Lactate Acrylates at $25{ }^{\circ} \mathrm{C}$. This procedure is generic for all the polymerizations conducted herein. The polymerization of ELA with EBiB in EtOH under the following conditions: $[\mathrm{ELA}]_{0} /[\mathrm{EBiB}]_{0} /\left[\mathrm{Me}_{6}-\mathrm{TREN}\right]_{0}=50 / 1 / 0.1$ is described. ELA $(1 \mathrm{~mL}, 6.23 \mathrm{mmol}), \mathrm{EtOH}(0.5$ $\mathrm{mL}), \mathrm{Me}_{6}-\mathrm{TREN}(3.3 \mu \mathrm{L}, 0.01 \mathrm{mmol})$ and $\mathrm{EBiB}(18.3 \mu \mathrm{L}, 0.12 \mathrm{mmol})$ were introduced into a $25 \mathrm{~mL}$ Schlenk tube. The solution was deoxygenated by applying four freeze-pump ( 1 min)-thaw cycles. After that, a Teflon-coated stirring bar wrapped with $4.5 \mathrm{~cm}$ of hydrazine-activated $\mathrm{Cu}(0)$ wire of 20 gauge was loaded under positive argon pressure. Then, two additional freeze-pump ( $1 \mathrm{~min})$-thraw cycles were applied before placing the flask in a water bath at $25^{\circ} \mathrm{C}$ and introducing the stirring bar wrapped with the $\mathrm{Cu}(0)$ wire catalyst into the reaction mixture. To monitor the monomer conversion, the side arm of the tube was purged with argon before it was opened to remove two drops of sample using an airtight syringe. Samples were dissolved in $\mathrm{CDCl}_{3}$ and quenched by air bubbling. After that, the monomer conversion was determined by ${ }^{1} \mathrm{H}$ NMR spectroscopy and $M_{n}$ and $M_{w} / M_{n}$ values by GPC using PMMA standards. Finally, to stop the reaction, the Schlenk flask was opened to air, and the polymerization mixture was dissolved in $2 \mathrm{~mL}$ of $\mathrm{CH}_{2} \mathrm{Cl}_{2}$. Next, the resulting solution was precipitated twice in $100 \mathrm{~mL}$ of hexane with vigorous 
stirring. The solvent was removed by filtration, and the final polymer was dried under vacuum until constant weight.

Thio-Bromo "Click" Modification of poly(ELA) Using Thiophenol. A solution of polymer $\left(0.3 \mathrm{~g}, M_{n}^{\text {th }}=\right.$ $4370 \mathrm{~g} / \mathrm{mol})$ in $\mathrm{MeCN}(1 \mathrm{~mL})$ was prepared in a $10 \mathrm{~mL}$ vial equipped with a rubber septum. Then, thiophenol ( $23.3 \mu \mathrm{L}, 0.227 \mathrm{mmol})$ and TEA $(31.7 \mu \mathrm{L}, 0.227 \mathrm{mmol})$ were added. The reaction was allowed to proceed for $4 \mathrm{~h}$ at room temperature and then added dropwise into $10 \mathrm{~mL}$ of hexanes with vigorous stirring. The resulting modified poly(ELA) was washed twice with fresh solvent and dried under vacuum until constant weight before MALDI-TOF analysis.

In Situ Block Copolymerization of Poly(ELA) by Cu(0)-Catalyzed SET-LRP in Ethanol. This procedure was used for both copolymerizations with SA and $\alpha$ PA. The block copolymerization of poly(ELA) $\left([\mathrm{ELA}]_{0} /[\mathrm{EBiB}]_{0} /\left[\mathrm{Me}_{6}-\mathrm{TREN}\right]_{0}=50 / 1 / 0.1\right)$ with $\alpha \mathrm{PA}$ (50 equiv) is described. A solution of the ELA (1 $\mathrm{mL}, 6.23 \mathrm{mmol}), \mathrm{EtOH}(0.5 \mathrm{~mL}), \mathrm{Me}_{6} \mathrm{TREN}(3.3 \mu \mathrm{L}, 0.01 \mathrm{mmol})$ and $\mathrm{EBiB}(18.3 \mu \mathrm{L}, 0.12 \mathrm{mmol})$ was prepared in a $25 \mathrm{~mL}$ Schlenk tube. After following the deoxygenation procedure described above, $\mathrm{Cu}(0)$ catalyst ( $4.5 \mathrm{~cm}$ of gauge 20 wire, wrapped around a Teflon-coated stir bar) was introduced into the flask under positive pressure of argon. Next, two additional freeze-pump ( 1 min)-thaw cycles were applied before placing the flask in a water bath at $25^{\circ} \mathrm{C}$ and introducing the stirring bar wrapped with the catalyst into the reaction mixture. After $3 \mathrm{~h}$ the side arm of the tube was purged with argon before it was opened to determine monomer conversion and introduce a degassed solution containing the $\alpha \mathrm{PA}(1.3 \mathrm{~mL}, 6.27$ mmol) in EtOH $(0.7 \mathrm{~mL})$ containing $\mathrm{Me}_{6}-\mathrm{TREN}(3.3 \mu \mathrm{L}, 0.01 \mathrm{mmol})$ via cannula. After stirring the polymerization mixture for $24 \mathrm{~h}$ at $25^{\circ} \mathrm{C}$, conversion of the second monomer was determined by ${ }^{1} \mathrm{H}$ NMR and the polymerization mixture was dissolved the minimum DCM and precipitated in cold methanol. The final copolymer poly(ELA)- $b$-poly $(\alpha \mathrm{PA})$ was dried under vacuum until constant weight. 
Preparation and Characterization of Amphiphilic Block Copolymer poly(ELA)-b-poly(GA) micelles. Polymer micelles were prepared by nanoprecipitation as follows: $1 \mathrm{mg}$ of poly(ELA)-b-poly(GA) copolymer was first dissolved in acetone $(1 \mathrm{~mL})$. This solution was added dropwise into $10 \mathrm{~mL}$ of deionized water via a syringe. The colloidal dispersion was sonicated for $4 \mathrm{~h}$ at room temperature to remove the organic solvent. The critical micelle concentration (CMC) was determined by using pyrene as a fluorescence probe by monitoring the emission peaks at 382 and $372 \mathrm{~nm}$. The concentration of block copolymer was ranging from $1.0 \times 10^{-9}$ to $1.0 \times 10^{-3} \mathrm{~g} \mathrm{~L}^{-1}$ and the pyrene concentration was fixed at $6.0 \mathrm{x}$ $10^{-7} \mathrm{M}$.

\section{RESULTS AND DISCUSSION}

Synthesis of Ethyl Lactate Acrylate. As illustrated in Scheme 2a, the acryloyl polymerizable functionality was installed on EL, commercially produced from sugarcane by fermentation, by acylation with acryloyl chloride in the presence of trimethylamine (TEA) using dichloromethane (DCM) as solvent. ELA was isolated as a colorless liquid after work up and vacuum distillation in the presence of hydroquinone to minimize auto-polymerization (70\% yield). The synthesis of the monomer was confirmed by NMR and FTIR spectroscopy (Figures S1-3). The acrylic protons appear in the ${ }^{1} \mathrm{H}$ NMR spectrum between 6.50 and $5.88 \mathrm{ppm}$, whereas the four characteristic signals of the vinylic and carbonyl carbons appear in the ${ }^{13} \mathrm{C}$ NMR spectrum at 170, 165 and 131, $127 \mathrm{ppm}$, respectively. 
Scheme 1. Chemical Structures of (a) Bio-Based Acrylates and (b) Initiators used in this Study

a)

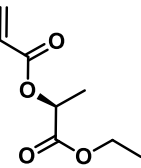

ELA<smiles>C=CC(=O)OC(C)C(=O)OC</smiles>

MLA

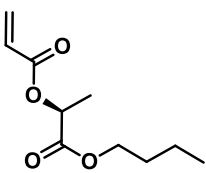

BLA

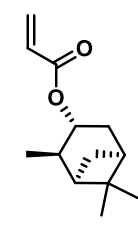

PA

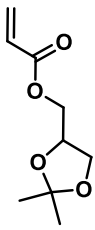

SA

b)

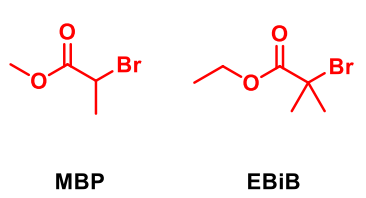

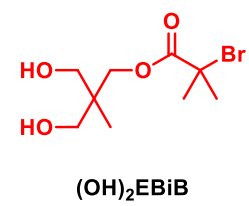

Scheme 2. Synthetic Routes to ELA Starting from EL Solvent

a)<smiles>C=CC(=O)C(C)C(=O)OCC</smiles>

b)

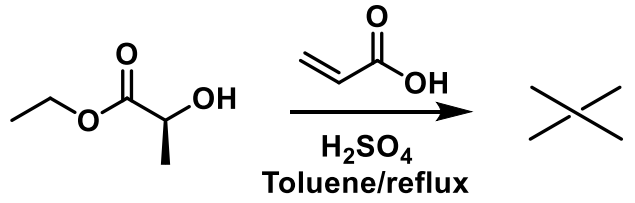

c)

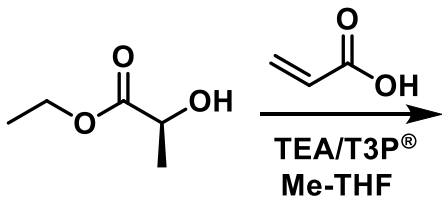<smiles>C=CC(=O)OC(C)C(=O)OCC</smiles><smiles>C=CC(=O)OC(C)C(=O)OCC</smiles>

FTIR spectroscopy showed characteristic absorptions of the two ester moieties at 1748 and $1726 \mathrm{~cm}^{-1}$ and the stretching of the acrylate $\mathrm{C}=\mathrm{C}$ bond at around $1637 \mathrm{~cm}^{-1}$. An additional structure confirmation was provided by high-resolution mass spectrometry (see experimental section). Supercritical fluid chromatography (SFC) was used for analytical chiral separation of the synthesized monomer (Figure S4). On the basis of this analysis and optical rotation measurements $\left([\alpha]_{\mathrm{D}}{ }^{25}=-53.9, c 1.0 \mathrm{mg} / \mathrm{mL}, \mathrm{MeCN}\right)$, ELA employed was L-(-)-ELA with 96.7\% enantiomeric excess. Being critical with the sustainability of the above described procedure, two alternative greener routes were explored in attempt to prepare ELA 
with the aid of acrylic acid (Scheme $2 b$ and $c$ ). It is worth to mention that with the recent developments toward the commercial production of bio-acrylic acid and the cost-competitive production of bio-ethanol, ELA may be ultimately prepared entirely from biomass derived platform chemicals. ${ }^{3}$ Unfortunately, the acrylic acid/EL acid-catalyzed esterification by azeotropic distillation in toluene was low-yield because extensive oligomerization of EL occurred at high temperature. ${ }^{46}$ Conversely, the use of propylphosphonic anhydride $\left(\mathrm{T}^{\mathrm{P}} \mathrm{P}^{\circledR}\right)$ under milder conditions gave an excellent result. ${ }^{52}$ This ester coupling promoter lacks the toxicity and shock sensibility associated with other coupling agents (e.g. DCC and EDC) ${ }^{54}$ Moreover, by-products from the coupling are $\mathrm{H}_{2} \mathrm{O}$-soluble and therefore easily separated from the reaction mixture. Using the biomass-derived 2-methyl-tetrahydrofuran (Me-THF) as solvent and a slight excess of acrylic acid in combination with TEA, ${ }^{1} \mathrm{H}$ NMR analysis confirmed the nearly quantitative esterification of EL with acrylic acid. Despite due to low scale reaction, ELA was purified in this case by flash column chromatography. This route represents a more attractive approach to ELA and other alkyl lactate ester acrylates from a green chemistry point of view.

Selection of Initiator for SET-LRP of ELA in DMSO. The polymerization of ELA was investigated employing the simpler SET-LRP methodology which uses $\mathrm{Cu}(0)$ wire wrapped around a stirring bar. Our preliminary investigations were devoted to select the optimal initiator for the polymerization of ELA using tris[2-(dimethylamino)ethyl]amine ( $\left.\mathrm{Me}_{6}-\mathrm{TREN}\right)$ as ligand in DMSO (50 vol\%) at $25^{\circ} \mathrm{C}$ (Scheme 3 ). This powerful dipolar aprotic solvent is always one of the preferred options to practice SET-LRP because promotes extensive disproportionation of $\mathrm{Cu}(\mathrm{I}) \mathrm{X}$ in the presence of $N$-ligands such as $\mathrm{Me}_{6}$-TREN and tris(2-aminoethyl)amine (TREN). ${ }^{21,22}$ 
Scheme 3. $\mathrm{Cu}(0)$ Wire-Catalyzed SET-LRP of ELA Initiated with MBP or EBiB using Me 6 -TREN Ligand in Various Solvents at Room Temperature. Solvents used here are DMSO, EtOH, MeOH, 2-PrOH, TFE, EL and Aqueous EL Mixtures
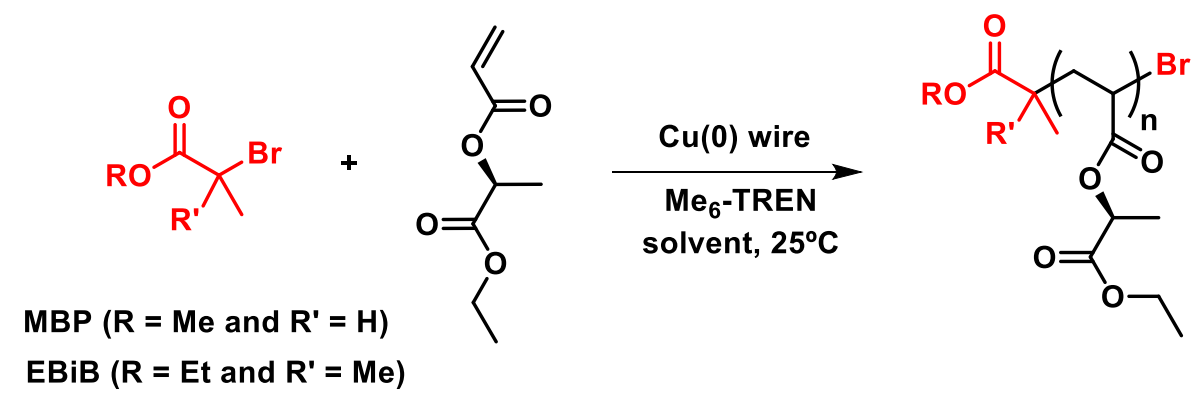

a) $[\mathrm{ELA}]_{0} /[\mathrm{MBP}]_{0} /\left[\mathrm{Me}_{6}-\mathrm{TREN}\right]_{0}=$

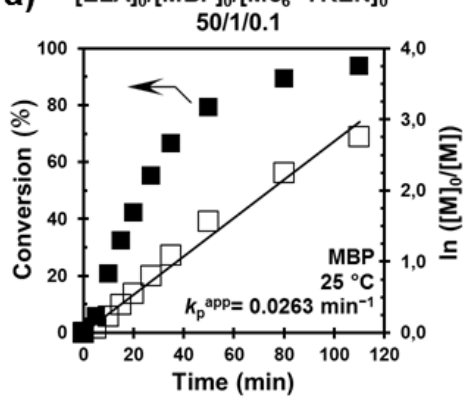

b) $[\mathrm{ELA}]_{0} /[\mathrm{EBiB}]_{0} /\left[\mathrm{Me}_{6}-\mathrm{TREN}\right]_{0}=$

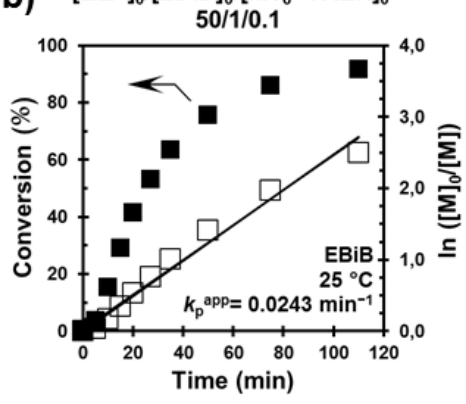

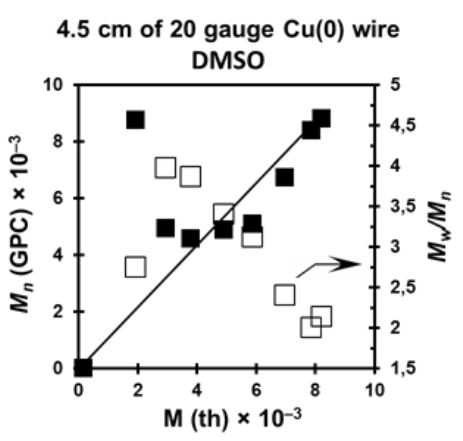

$4.5 \mathrm{~cm}$ of 20 gauge $\mathrm{Cu}(0)$ wire

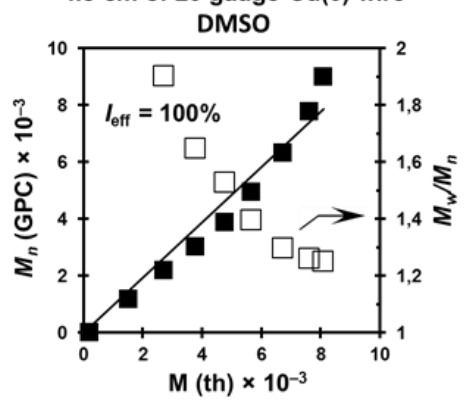

c)<smiles>COC(=O)C(Br)Br</smiles><smiles>CCOC(=O)C(C)(C)Br</smiles>

EBiB

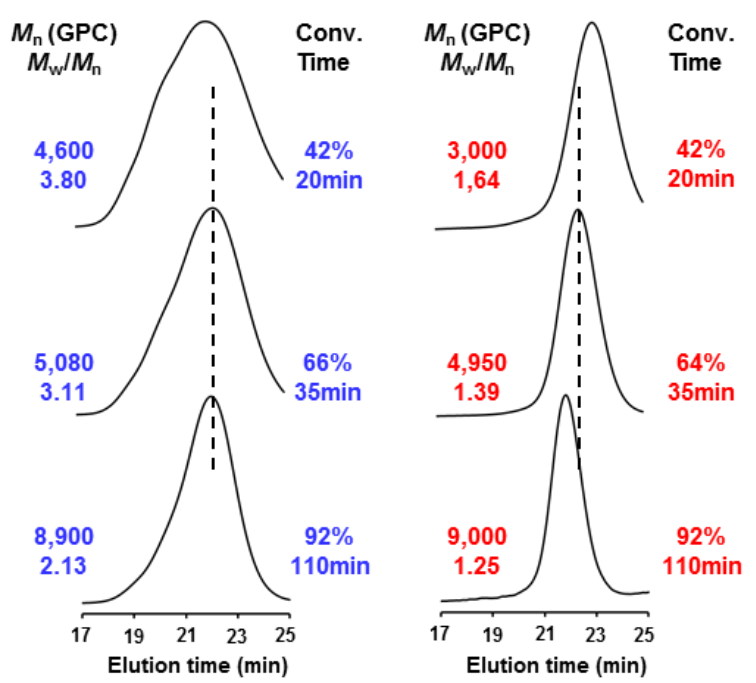

Figure 1. Monomer conversion, kinetics plots and evolution of experimental $M_{\mathrm{n}}(\mathrm{GPC})$ and $M_{\mathrm{w}} / M_{\mathrm{n}}$, based on the calibration by PMMA standards, versus theoretical M(th) for the SET-LRP of ELA initiated with $\mathrm{MBP}(\mathrm{a})$ and $\mathrm{EBiB}(\mathrm{b})$ in DMSO at $25^{\circ} \mathrm{C}$. Reaction conditions: ELA $=1 \mathrm{~mL}$, DMSO $=0.5 \mathrm{~mL}$, $[\text { ELA }]_{0} /[\text { Initiator }]_{0} /\left[\mathrm{Me}_{6}-\mathrm{TREN}\right]_{0}=50 / 1 / 0.1$ using $4.5 \mathrm{~cm}$ of hydrazine-activated $\mathrm{Cu}(0)$ wire $(20$-gauge diameter). (c) GPC traces (normalized to peak height) for the poly(ELA) obtained from kinetic experiments. 
Table 1. $\mathrm{Cu}(0)$ Wire-Catalyzed SET-LRP of ELA in DMSO and Conventional Alcohols at $25^{\circ} \mathrm{C} .^{\text {a }}$

\begin{tabular}{|c|c|c|c|c|c|c|c|c|c|}
\hline entry & $\begin{array}{l}\text { reaction } \\
\text { medium }\end{array}$ & initiator & $\begin{array}{c}{[\text { ELA }]_{0} /[\text { Initiator }]_{0} /\left[\mathrm{Me}_{6-}\right.} \\
\text { TREN }]_{0}\end{array}$ & $k_{\mathrm{p}}^{\text {app }}$ & $\begin{array}{l}\text { time } \\
(\mathrm{min})\end{array}$ & $\begin{array}{c}\text { conv. }^{\text {b }} \\
(\%)\end{array}$ & $M(t h)^{c}$ & $M_{n}^{d}$ & $M_{w} / M_{n}^{d}$ \\
\hline 1 & DMSO & MBP & $50 / 1 / 0.1$ & 0.0263 & 110 & 94 & 8,225 & 8.800 & 2.13 \\
\hline 2 & DMSO & $\mathrm{EBiB}$ & $50 / 1 / 0.1$ & 0.0243 & 110 & 92 & 8,000 & 9,000 & 1.25 \\
\hline 3 & DMSO & MBP & $50 / 1 / 0.1^{\mathrm{e}}$ & 0.0263 & 110 & 94 & 8,225 & 7,970 & 1.18 \\
\hline 4 & $\mathrm{EtOH}$ & $\mathrm{EBiB}$ & $50 / 1 / 0.1$ & 0.0315 & 75 & 94 & 8,320 & 8,400 & 1.19 \\
\hline 5 & $\mathrm{MeOH}$ & $\mathrm{EBiB}$ & $50 / 1 / 0.1$ & - & 120 & 96 & 8,460 & 9,660 & 1.20 \\
\hline 6 & 2-PrOH & $\mathrm{EBiB}$ & $50 / 1 / 0.1$ & - & 120 & 95 & 8,375 & 8,560 & 1.30 \\
\hline 7 & TFE & $\mathrm{EBiB}$ & $50 / 1 / 0.1$ & 0.0251 & 110 & 93 & 8,150 & 8,590 & 1.17 \\
\hline 8 & $\mathrm{EtOH}$ & $\mathrm{EBiB}$ & $25 / 1 / 0.1$ & - & 240 & 97 & 4,370 & 4,120 & 1.22 \\
\hline 9 & $\mathrm{EtOH}$ & $\mathrm{EBiB}$ & $100 / 1 / 0.2$ & - & 240 & 94 & 16,400 & 18,150 & 1.22 \\
\hline 10 & $\mathrm{EtOH}$ & $\mathrm{EBiB}$ & $200 / 1 / 0.5$ & - & 240 & 95 & 32,700 & 34,700 & 1.20 \\
\hline 11 & $\mathrm{EtOH}$ & $\mathrm{EBiB}$ & $400 / 1 / 0.5$ & - & 240 & 95 & 65,620 & 64,300 & 1.23 \\
\hline
\end{tabular}

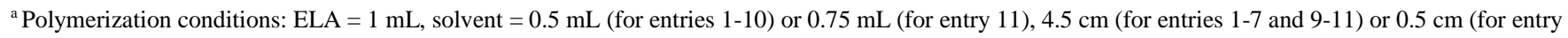
8) of hydrazine-activated $\mathrm{Cu}(0)$ wire $\left(20\right.$-gauge diameter). ${ }^{\mathbf{b}}$ Determined by ${ }^{1} \mathrm{H}$ NMR. ${ }^{\mathbf{c}} \mathrm{M}($ th $)=172.18 \times[\mathrm{ELA}]_{0} /[\mathrm{EBiB}]_{0} \mathrm{x}$ conv. $+195.05 .{ }^{\mathrm{e}}$ Determined by GPC using PMMA standards. ${ }^{e}$ Reaction conducted in the presence of $5 \mathrm{~mol} \%$ of externally added $\mathrm{Cu}(\mathrm{II}) \mathrm{Br}_{2}$.

Moreover, it stabilizes the resulting colloidal $\mathrm{Cu}(0)$ particles and at the same time is also a good solvent for $\mathrm{Cu}(\mathrm{II}) \mathrm{X}_{2}$ ligand complex. ${ }^{55}$ Figure 1a,b depicts kinetic plots and GPC analysis for the polymerization using the monofunctional initiators methyl $\alpha$-bromopropionate (MBP) and ethyl $\alpha$-bromoisobutyrate $(\mathrm{EBiB})$ at a targeted degree of polymerization (DP) of 50 (entries 1 and 2 in Table 1). ${ }^{1} \mathrm{H}$ NMR analysis of regularly withdrawn samples from the homogeneous reaction mixtures was used to monitor monomer consumption during the reaction. Both polymerizations proceeded up to above $90 \%$ conversion in 110 min, confirming the generation of propagating radical from initiator. However, GPC analysis showed that there exist important differences between both initiating systems (Figure 1c). For example, significant deviation between the experimental $\left(M_{\mathrm{n}}(\mathrm{GPC})\right)$ and theoretical $(\mathrm{M}(\mathrm{th}))$ molecular weight values of the resulting poly(ELA) was observed during the polymerization with MBP up to approximately $30 \%$ monomer conversion. Moreover, polydispersity $\left(M_{\mathrm{w}} / M_{\mathrm{n}}\right)$ in this case did not decrease below 2.1. These results suggest slow initiator rate when compared with propagation and/or slower rate of deactivation. In stark contrast, molar mass increased monotonically and linearly with theoretical values when using the 
tertiary initiator $\mathrm{EBiB}$ (Figure 1b, right). In this case, only a subtle molecular weight deviation, probably due to the bimolecular combination reaction between the propagating polymer chains, was observed at high conversion. Overall, the tertiary initiator $(\mathrm{EBiB})$ provided much higher degree of control over the molecular weight distribution (MWD) resulting in poly(ELA) with narrow $M_{\mathrm{w}} / M_{\mathrm{n}}$ (1.25 compared to 2.13). This result, combined with a linear increase of $\ln [\mathrm{M}] \mathrm{o} /[\mathrm{M}]$ with time up to high conversion, suggest living polymerization features for the reaction initiated with $\mathrm{EBiB}$. These observations are consistent with the fact that tertiary $\alpha$-haloester-type initiators are better electronic mimics for conventional acrylates. ${ }^{56}$ Notably, the use of MBP initiator in the presence of $5 \mathrm{~mol} \%$ externally added $\mathrm{Cu}(\mathrm{II}) \mathrm{Br}_{2}$ deactivator, with respect to initiator concentration under otherwise identical conditions, yielded an important improvement over the MWD $\left(M_{\mathrm{w}} / M_{\mathrm{n}}=1.19\right)$ (entry 3 in Table 1 and Figure S5). However, we preferred using EBiB and other mono and bifunctional bromoisobutyrate derivatives, in absence of externally added deactivator, for the rest of this study.

\section{Selection of Eco-Friendly Solvents for SET-LRP of Ethyl Lactate Acrylate}

Ethanol and other Conventional Alcohols. A more environmentally friendly process for the SET-LRP of ELA was devised through the use of alcohols as solvents because they combine both acceptable levels of $\left[\mathrm{Cu}(\mathrm{I})\left(\mathrm{Me}_{6}-\mathrm{TREN}\right) \mathrm{Br}\right]$ disproportionation and low environmental impact. ${ }^{17,57,58,59,60} \mathrm{We}$ first focused our attention on ethanol (EtOH), the oldest and most successful bio-sourced chemical solvent. The kinetics of the polymerization for the $\mathrm{Cu}(0)$ wire-catalyzed SET-LRP of ELA in EtOH using EBiB was investigated under identical conditions to the experiment in DMSO (entry 4 in Table 1 and Figure 2a). Also in this case, the reaction mixture remained homogeneous through the entire reaction course. The time evolution of $\ln \left([\mathrm{M}]_{0} /[\mathrm{M}]\right)$ was linear up to monomer conversion above $90 \%$, which is consistent with a constant

concentration of propagating radicals during the homopolymerization reaction. In addition, molecular 
weights values were in excellent agreement with theoretical prediction (i.e. living polymerization). Surprisingly, the SET-LRP in EtOH was even faster than in DMSO $\left(k_{\mathrm{p}}{ }^{\text {app }}=0.0315 \mathrm{~min}^{-1}\right.$ compared to $\left.0.0243 \mathrm{~min}^{-1}\right)$. Indeed, it delivered a polymer with narrower $\operatorname{MWD}\left(M_{\mathrm{w}} / M_{\mathrm{n}}=1.19\right.$ compared to 1.25$)$.
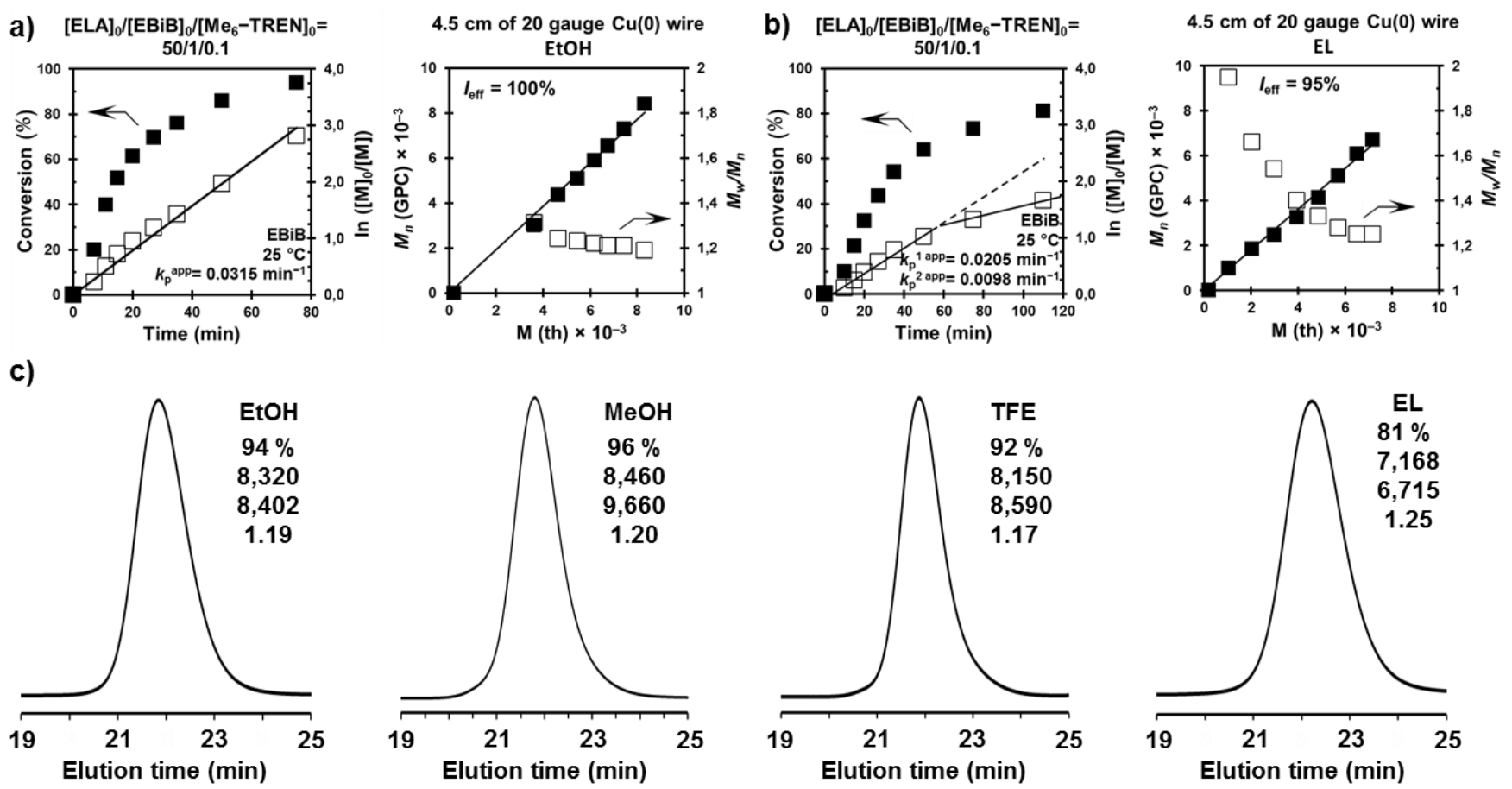

Figure 2. Monomer conversion, kinetics plots and evolution of experimental $M_{\mathrm{n}}(\mathrm{GPC})$ and $M_{\mathrm{w}} / M_{\mathrm{n}}$, based on the calibration by PMMA standards, versus theoretical M(th) for the SET-LRP of ELA initiated with $\mathrm{EBiB}$ in (a) $\mathrm{EtOH}$ and (b) $\mathrm{EL}$ at $25^{\circ} \mathrm{C}$. (c) GPC traces (normalized to peak height) for the poly(ELA) isolated after SET-LRP polymerization of ELA in EtOH, MeOH, TFE and EL. Reaction conditions: ELA $=1 \mathrm{~mL}$, alcohol $=0.5 \mathrm{~mL},[\mathrm{ELA}]_{0} /[\mathrm{EBiB}]_{0} /\left[\mathrm{Me}_{6}-\mathrm{TREN}\right]_{0}=50 / 1 / 0.1$, and $4.5 \mathrm{~cm}$ of hydrazine-activated $\mathrm{Cu}(0)$ wire (20-gauge diameter). Numbers shown in black in (c) correspond to monomer conversion, $\mathrm{M}$ (th), $M_{\mathrm{n}}(\mathrm{GPC})$, and $M_{\mathrm{w}} / M_{\mathrm{n}}$ respectively from the top to bottom.

As shown in Figure 2c, other conventional alcohols having similar solvent properties such as methanol $(\mathrm{MeOH})$ could also be used to prepare well-defined poly(ELA) (entries 5 in Table 1). The reaction in propan-2-ol (2-PrOH) furnished a polymer with higher $M_{\mathrm{w}} / M_{\mathrm{n}}$ (entries 6 in Table 1). However, in a fluorinated alcohol such as 2,2,2-trifluoroethanol (TFE), $M_{\mathrm{w}} / M_{\mathrm{n}}$ was as low as 1.17 (entry 7 in Table 1 
and Figure 2c). The kinetic plots for the polymerization in TFE also validates the use of fluorinated alcohols (Figure S6). ${ }^{61,62,63}$

Pushing the envelope of the ethanolic SET-LRP, we further investigated its potential in delivering welldefined poly(ELA) across a broad range of molecular weight while retaining control. Thus, a series of polymerizations were conducted varying the targeted DPs from 25 to 400 (entries 8-11 in Table 1). In all cases, SET-LRP smoothly proceeded at $25^{\circ} \mathrm{C}$ to high monomer conversions (>90\%), yielding polymers with controlled molecular weight up to 65,000 (Figure 3).

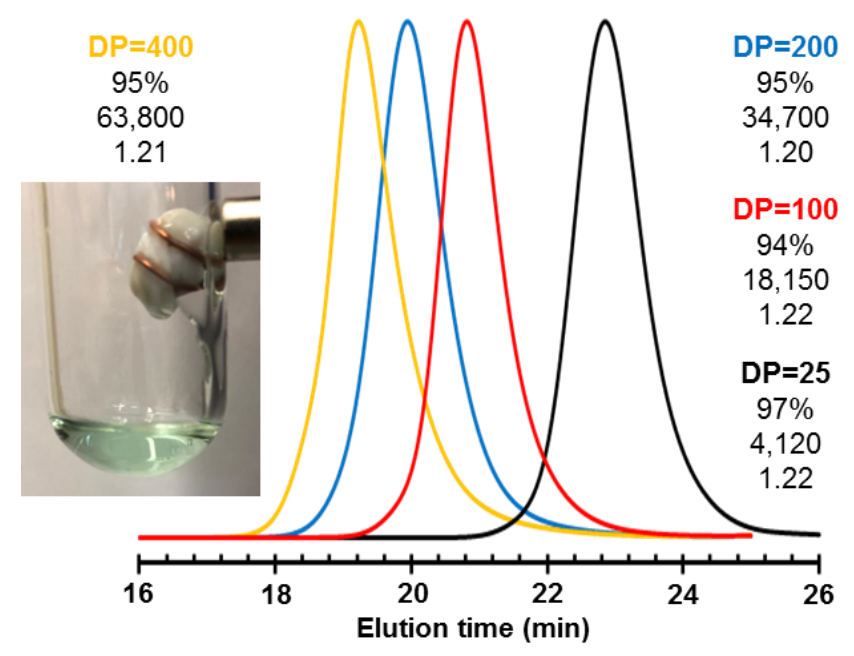

Figure 3. GPC traces (normalized to peak height) of poly(ELA) with different targeted DPs (see entries 8-11 in Table 1 for polymerization conditions). The inset shows a digital image of the homogeneous reaction mixture after ethanolic SET-LRP at targeted DP=400. Numbers shown in black correspond to monomer conversion, $M_{\mathrm{n}}(\mathrm{GPC})$, and $M_{\mathrm{w}} / M_{\mathrm{n}}$ respectively from the top to bottom.

It is worth to mention that the SET-LRP at DP=400 was still homogeneous at high conversion, suggesting good solubility of poly(ELA) in this protic solvent environment (Figure 3, inset). Despite using a monofunctional initiator, no shoulders in the GPC curves and $M_{\mathrm{w}} / M_{\mathrm{n}} \sim 1.20$ for all the polymers suggesting minimal side reactions such as bimolecular termination and high end-group fidelity. This was further confirmed by the structural characterization of the lowest molar mass poly(ELA) $\left(M_{\mathrm{n}}=4,120, M_{\mathrm{w}} / M_{\mathrm{n}}=\right.$ 1.22). 
a)
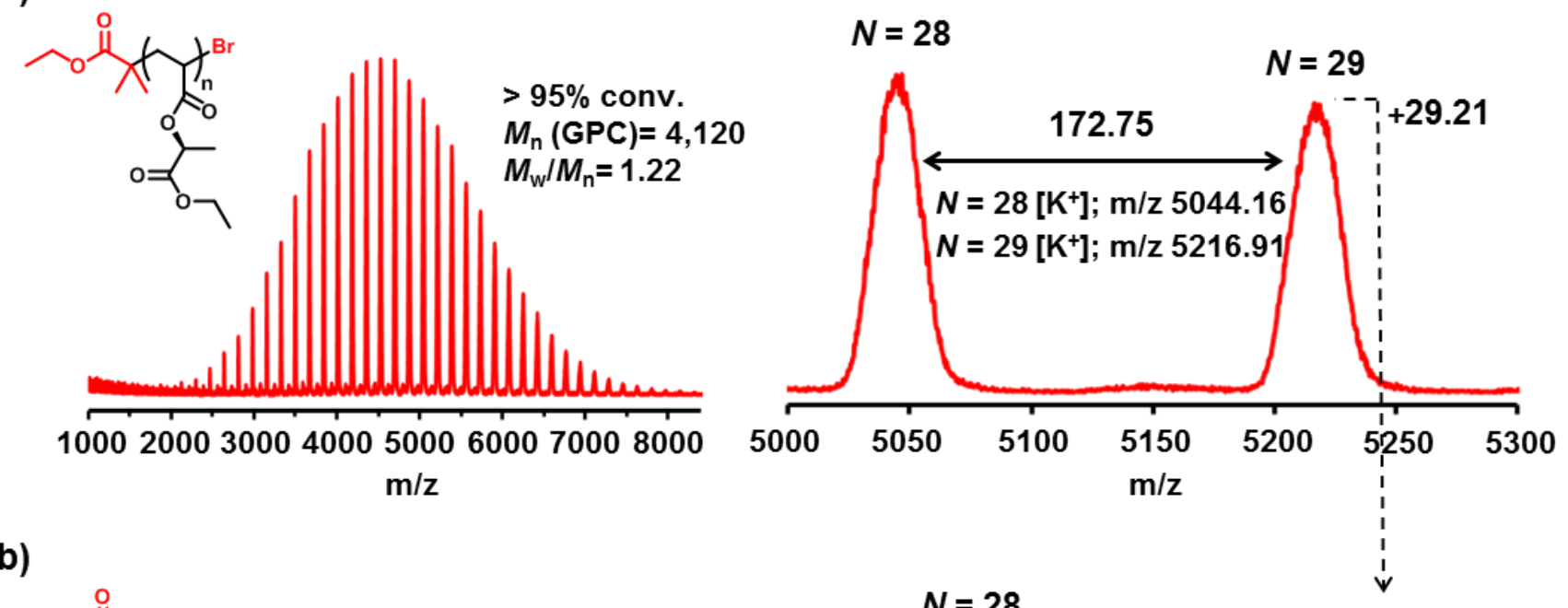

b)
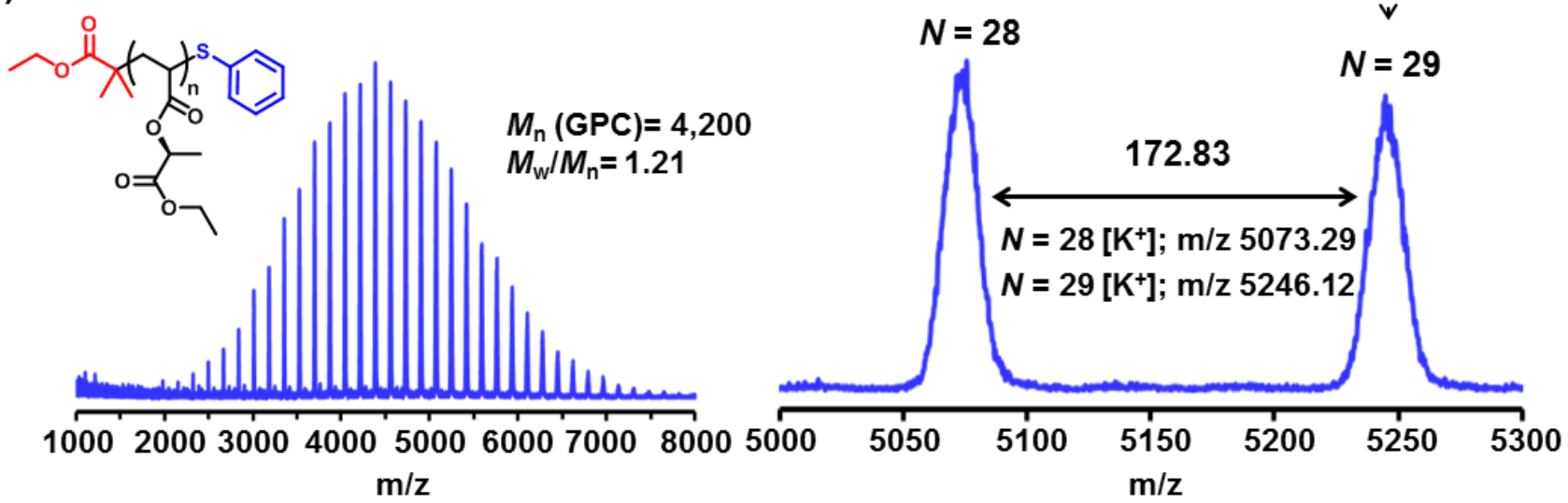

Figure 4. MALDI-TOF spectra of poly(ELA) obtained at $97 \%$ conversion before and after thio-bromo "click" modification with thiophenol. Magnified regions confirm the expected peak-to-peak spacing for ELA repeating unit and the near perfect bromine chain end functionality of the synthesized polymer.

Unfortunately, bromine end-group functionality could not be evaluated by ${ }^{1} \mathrm{H}$ NMR due to the overlapping of the signal corresponding to both $\alpha$ and $\omega$ chain ends with the methylene signal of the pendant ethyl ester groups (Figure S7). However, according to MALDI-TOF analysis, the chain-end functionality was well-maintained after the SET-LRP process (Figure 4). The spectrum of poly(ELA) isolated at near quantitative conversion (>95\%) shows a dominant distribution of peaks, having a peakto-peak mass increment of $172 \mathrm{Da}$, which equals to the mass of a single repeating unit (Figure 4a). The $\mathrm{m} / \mathrm{z}$ values of these peaks match the expected $[\mathrm{M}+\mathrm{K}]^{+} \omega$-bromo-terminated chains. Moreover, after thio- 
bromo "click" post-polymerization modification with thiophenol, ${ }^{64,65}$ this series completely vanished and meanwhile a new series of peaks emerged 29 Da above (Figure 4b). This mass difference is consistent with the thioetherification at the $\omega$-bromo chain ends with thiophenol. Overall, MALDI-TOF analysis before and after end-group modification confirmed minimal side reactions and high bromine chain endgroup fidelity after SET-LRP, which combined with near quantitative monomer conversions at various DPs is expected to enable the straightforward synthesis of poly(ELA)-derived block copolymers by in situ sequential addition of a second monomer (vide infra).

Ethyl Lactate and Aqueous Ethyl Lactate Mixtures. Encouraged by these results, the polymerization of ELA was investigated in detail using its bio-sourced synthetic precursor EL as solvent. EL is an economically viable green solvent with effectiveness comparable to some petroleum-based solvents. ${ }^{42,43,44,45}$ Replacing EtOH by EL, under identical conditions, also furnished poly(ELA) with narrow MWD (entry 1 in Table 2 and Figure 2c). However, despite the fact that poly(ELA) was also soluble in this solvent the reaction achieved lower monomer conversion (compare entry 1 in Table 2 with entry 4 in Table 1). Unexpectedly, the plot of $\ln \left([\mathrm{M}]_{0} /[\mathrm{M}]\right)$ versus time was linear only up to $50 \mathrm{~min}(60 \%$ monomer conversion) $\left(k_{\mathrm{p}}{ }^{1 \text { app }}=0.0205 \mathrm{~min}^{-1}\right)$ (Figure $\left.2 \mathrm{~b}\right)$. After, the polymerization proceeded following a second kinetic domain with a significantly lower rate constant $\left(k_{\mathrm{p}}^{2 \mathrm{app}}=0.0098 \mathrm{~min}^{-1}\right)$. According to previous reports, this result may be attributed to rapid activation combined with insufficient disproportionation, which favors bimolecular termination events between growing chains (i.e. loss of bromine chain ends). ${ }^{66,67,68,69,70,71}$ It has been previously demonstrated that the addition of small amount of $\mathrm{H}_{2} \mathrm{O}$ to poor disproportionation reaction mixtures can dramatically improve its ability to produce reactive $\mathrm{Cu}(0)$ and the needed levels of $\mathrm{Cu}(\mathrm{II}) \mathrm{X}_{2}$ deactivator to prevent irreversible termination of chains 
in early stages of SET-LRP reactions. ${ }^{66,67}$ Indeed, tuning EL with $\mathrm{H}_{2} \mathrm{O}$ and other co-solvents is a common strategy to create ideal conditions in organic synthesis. ${ }^{72,73}$

Table 2. $\mathrm{Cu}(0)$ Wire-Catalyzed SET-LRP of ELA Initiated with EBiB in EL and Aqueous EL Mixtures at $25^{\circ} \mathrm{C} .^{a}$

\begin{tabular}{|c|c|c|c|c|c|c|c|c|c|}
\hline entry & reaction medium & $\begin{array}{c}k_{\mathbf{p}}^{1 \text { lapp }} \\
\left(\min ^{-1}\right)\end{array}$ & $\begin{array}{c}k_{\mathbf{p}}^{2 \text { app }} \\
\left(\mathbf{m i n}^{-1}\right)\end{array}$ & $\begin{array}{c}k_{\mathrm{p}}^{1 \text { lapp }} \\
\text { increase }^{\mathrm{b}} \\
(\%)\end{array}$ & time (min) & $\begin{array}{c}\text { conv. }^{c} \\
(\%)\end{array}$ & $M(t h)^{d}$ & $M_{\mathrm{n}}^{\mathrm{e}}$ & $M_{w} / M_{n}{ }^{\mathrm{e}}$ \\
\hline 1 & EL & 0.0205 & 0.0098 & - & 110 & 81 & 7,168 & 6.715 & 1.25 \\
\hline 2 & EL & 0.0146 & 0.0035 & - & 220 & 81 & 14,140 & 14,200 & 1.26 \\
\hline 3 & $\mathrm{EL} / \mathrm{H}_{2} \mathrm{O} .(9.5 / 0.5, \mathrm{v} / \mathrm{v})$ & 0.0227 & 0.0106 & 55 & 110 & 83 & 14,050 & 14,330 & 1.22 \\
\hline 4 & $\mathrm{EL} / \mathrm{H}_{2} \mathrm{O} .(9 / 1, \mathrm{v} / \mathrm{v})$ & 0.0276 & - & 89 & 75 & 86 & 14,730 & 16,500 & 1.18 \\
\hline 5 & $\mathrm{EL} / \mathrm{H}_{2} \mathrm{O} .(8.5 / 1.5, \mathrm{v} / \mathrm{v})$ & 0.0344 & - & 135 & 75 & 90 & 15,520 & 18,700 & 1.19 \\
\hline
\end{tabular}

${ }^{\text {a }}$ Polymerization conditions: ELA $=1 \mathrm{~mL}$, solvent $=0.5 \mathrm{~mL}$, using $4.5 \mathrm{~cm}$ of hydrazine-activated $\mathrm{Cu}(0)$ wire $(20$-gauge diameter), $[\mathrm{ELA}]_{0} /[\mathrm{EBiB}]_{0} /\left[\mathrm{Me}_{6}-\mathrm{TREN}\right]_{0}=50 / 1 / 0.1$ (for entry 1), $[\mathrm{ELA}]_{0} /[\mathrm{EBiB}]_{0} /\left[\mathrm{Me}_{6}-\mathrm{TREN}\right]_{0}=100 / 1 / 0.2$ (for entries 2-5). ${ }^{\mathrm{b}}$ Increase of $k_{\mathrm{p}}{ }^{\text {app }}$ with respect to the $k_{\mathrm{p}}{ }^{\text {lapp }}$ from entry $2 .{ }^{\mathrm{c}}$ Determined by ${ }^{1} \mathrm{H} \mathrm{NMR} .{ }^{\mathrm{d}} \mathrm{M}(\mathrm{th})=172.18 \times[\mathrm{ELA}]_{0} /[\mathrm{EBiB}]_{0} \mathrm{X}$ conv $+195.06 .{ }^{\mathrm{e}}$ Determined by GPC using PMMA standards.

Inspired by these studies, a series of experiments were conducted in aqueous EL mixtures under the following conditions: $[\mathrm{ELA}]_{0} /[\mathrm{EBiB}]_{0} /\left[\mathrm{Me}_{6}-\mathrm{TREN}\right]_{0}=100 / 1 / 0.2$ (entries 2-5 in Table 2). The control experiment in pure EL showed again limited monomer conversion and loss of livingness manifested as kinetic plots with two linear regimes (Figure S8a). However, after the addition of $5 \% \mathrm{H}_{2} \mathrm{O}$ to EL the polymerization rate of the second linear regime significantly increased (3x). An increase on $k_{\mathrm{p}}{ }^{1 \text { app }}$ was also observed, but much lower $(1.5 \mathrm{x})$ than that determined for $k_{\mathrm{p}}{ }^{2 \mathrm{app}}$. To our delight, increasing further the $\mathrm{H}_{2} \mathrm{O}$ content completely eliminated $k_{\mathrm{p}}{ }^{2 \mathrm{app}}$ and generated the characteristic first order kinetic of a LRP processes. Figure 5a-c compares kinetic plots and GPC results for the polymerization in pure EL and EL/ $\mathrm{H}_{2} \mathrm{O}$ mixture $(9 / 1, \mathrm{v} / \mathrm{v})$. In the latter system, the reaction rate was even faster $\left(1.9 \mathrm{x}\right.$ compared to $k_{\mathrm{p}}{ }^{1 \text { app }}$ obtained in pure EL). The linear increase in $k_{\mathrm{p}}{ }^{\text {app }}$ for aqueous EL mixtures is determined by the higher polarity of $\mathrm{H}_{2} \mathrm{O}$ (Figure 5d, close symbols). Moreover, the high disproportionation constant of $\mathrm{Cu}(\mathrm{I}) \mathrm{Br}$ in $\mathrm{H}_{2} \mathrm{O}\left(\mathrm{K}_{\mathrm{d}}=0.89\right.$ $\mathrm{x} 10^{6}$ to $5.8 \times 10^{7}$ ) is crucial to improve control during initial stages of SET-LRP. ${ }^{74,75}$ Notably, GPC traces revealed the disappearance of the high molecular weight tailing observed in pure EL, which tend to 
indicate insufficient level of $\mathrm{Cu}(\mathrm{II}) \mathrm{Br}_{2}$ to mediate an effective deactivation of growing chains, in the presence of $\mathrm{H}_{2} \mathrm{O}$ (Figure $\mathrm{S} 9$ ).
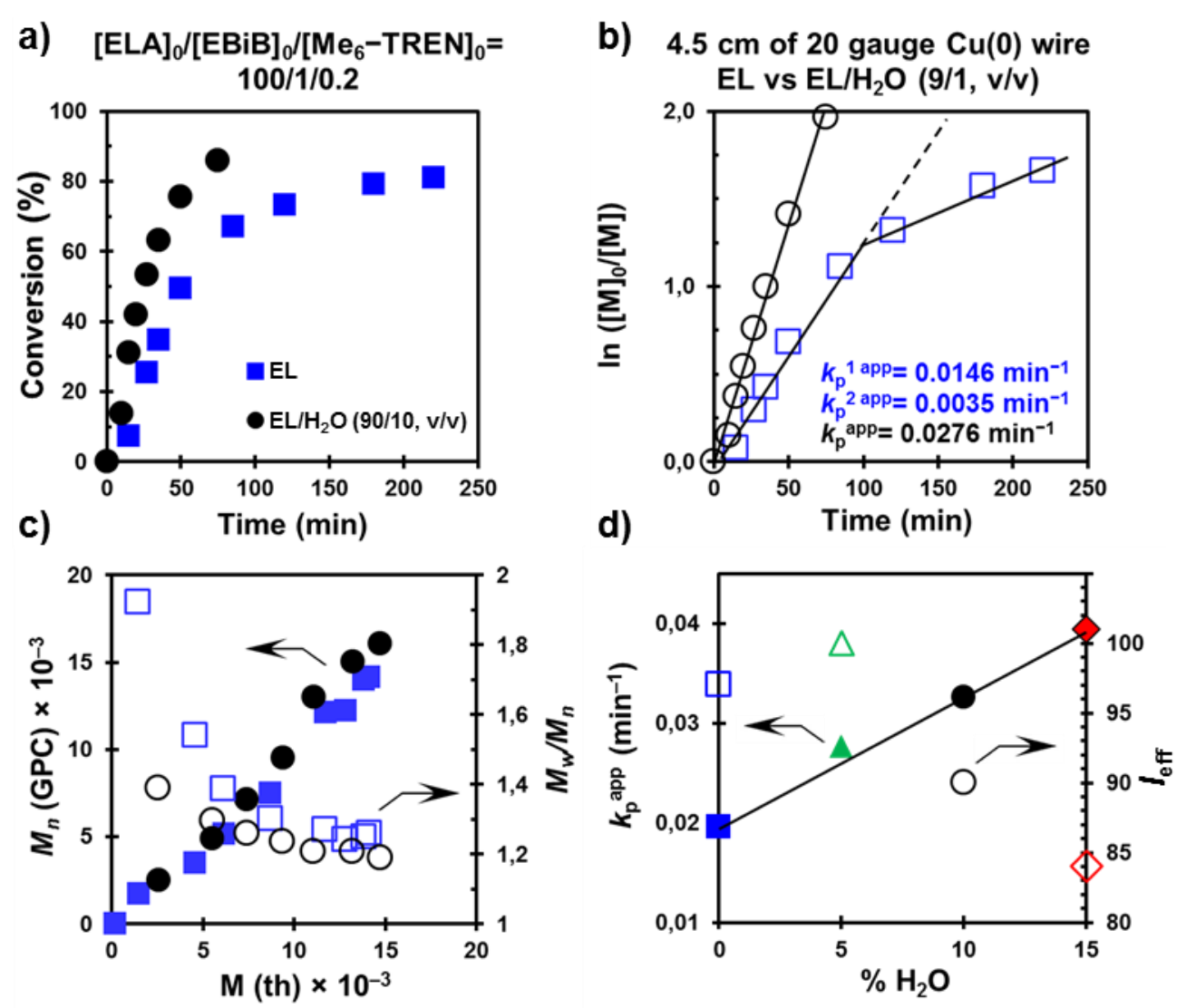

Figure 5. (a) Monomer conversion vs time, (b) $\ln [\mathrm{M}]_{0} /[\mathrm{M}]$ vs time and (c) evolution of experimental $\mathrm{M}_{n}$ (GPC) and $\mathrm{M}_{\mathrm{w}} / \mathrm{M}_{\mathrm{n}}$, based on the calibration by PMMA standards, versus theoretical M(th) for the SETLRP of ELA initiated with $\mathrm{EBiB}$ in $\mathrm{EL}$ (blue squares) and $\mathrm{EL} / \mathrm{H}_{2} \mathrm{O}$ (9/1, v/v) (black circles). (c) Dependence of $k_{\mathrm{p}}$ app and $I_{\text {eff }}$ with the percentage of $\mathrm{H}_{2} \mathrm{O}\left(\% \mathrm{H}_{2} \mathrm{O}\right)$. Reaction conditions: ELA $=1 \mathrm{~mL}$, solvent $=0.5 \mathrm{~mL},[\mathrm{ELA}]_{0} /[\mathrm{EBiB}]_{0} /\left[\mathrm{Me}_{6}-\mathrm{TREN}_{0}=100 / 1 / 0.2 \mathrm{using} 4.5 \mathrm{~cm}\right.$ of hydrazine-activated $\mathrm{Cu}(0)$ wire (20-gauge diameter).

Consequently, in the presence of $10 \%$, and even $5 \% \mathrm{H}_{2} \mathrm{O}$, better control over the MWD was obtained. Although EL is a good solvent for poly(ELA) and $\mathrm{EL} / \mathrm{H}_{2} \mathrm{O}$ mixtures are miscible at any composition, the SET-LRP reaction mixture of this series of experiments progressively transitioned from a one phase to a biphasic SET-LRP system by showing increasing turbidity (Figure S10). However, higher loadings of $\mathrm{H}_{2} \mathrm{O}$ only slightly compromise initiator efficiency $\left(I_{\text {eff }}\right)$ probably due to extremely fast activation and 
propagation in more polar media and not due to appearance of turbidity (Figure 5d, open symbols). Note that in the presence of $15 \% \mathrm{H}_{2} \mathrm{O}$, reaction rate was accelerated by $135 \%$ compared to $k_{\mathrm{p}}{ }^{\text {lapp }}$ obtained in pure EL (compare entries 2 and 5 in Table 3). These results demonstrate that the judicious selection of solvent is critical to practice SET-LRP and highlight the importance of mixed solvent systems.

Expanding the Range of Alkyl Lactate Ester Acrylates. To expand the scope of SET-LRP to other acrylic alkyl lactate ester derivatives, the homopolymerization of methyl lactate acrylate (MLA) and $n$ butyl lactate acrylate (BLA) was also investigated via ethanolic SET-LRP. Both monomers were synthesized, following the same procedure previously described for ELA, from the corresponding commercially available alkyl lactate ester. The kinetic experiments for $[\mathrm{MLA}]_{0} /[\mathrm{EBiB}]_{0} /\left[\mathrm{Me}_{6}-\mathrm{TREN}\right]_{0}=$ 100/1/0.2 and $[\mathrm{BLA}]_{0} /[\mathrm{EBiB}]_{0} /\left[\mathrm{Me}_{6}-\mathrm{TREN}\right]_{0}=50 / 1 / 0.1$ are shown in Figure S11. In both cases, the $\mathrm{Cu}(0)$ wire-catalyzed polymerization initiated by EBiB furnished well-defined polymers with high conversions (entries 1 and 2 in Table 3). No significant differences were found between the kinetic data in comparison with ELA (compare entry 2 in Table 3 with entry 4 in Table 1). Also in this case, the linear relationship of the semi-logarithmic kinetic plot and the linear increase of molecular weight values throughout the polymerization strongly support that the SET-LRP of these monomers follows a LRP mechanism. Further, the use of difunctional and hydoxyl-functional bromoisobutyrate-type initiators (bisEBiB and $(\mathrm{OH})_{2} \mathrm{EBiB}$, see Scheme 1) allowed the preparation of well-defined $\alpha, \omega$-dibromo telechelic and $\alpha, \alpha$-dihydroxy functional polymers (entries 3 and 4 in Table 3 and Figure 6a). MALDI-TOF analysis evidenced the very high end-group fidelity for the poly(BLA) functional polymer (Figure 6b). These materials could be interesting in the preparation of more complex polymer architectures based on alkyl lactate acrylic polymers including $\mathrm{ABA}$ triblocks and $\mathrm{AB}_{2}$ stars using $\mathrm{LRP}$ or other living polymerization reactions in a second step. Research in this line will be reported in a forthcoming publication. 
a)

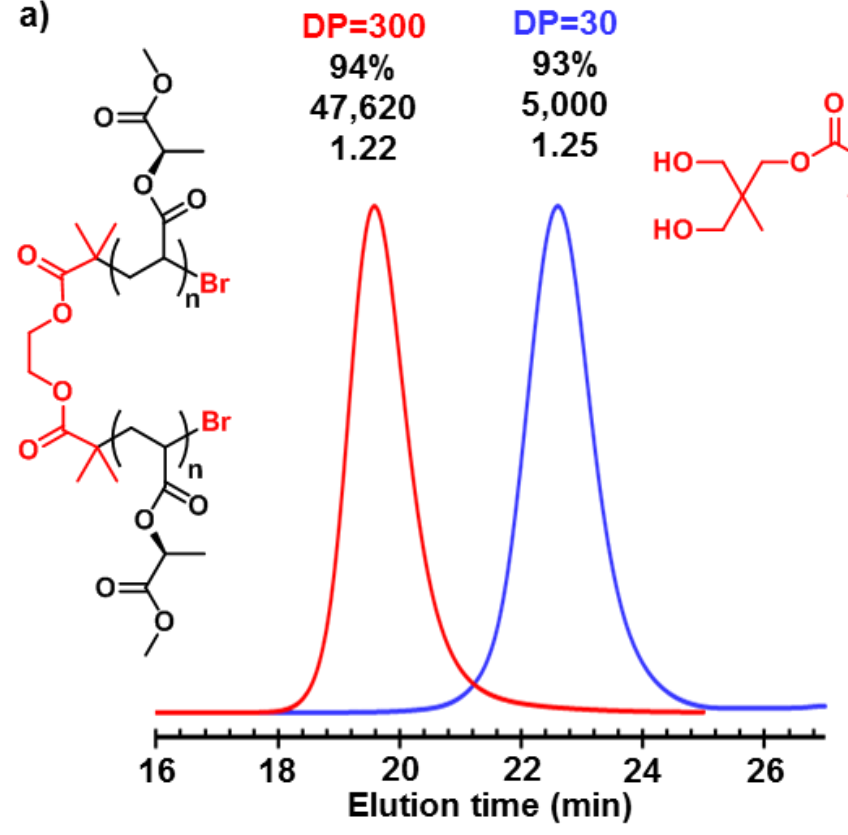

b)

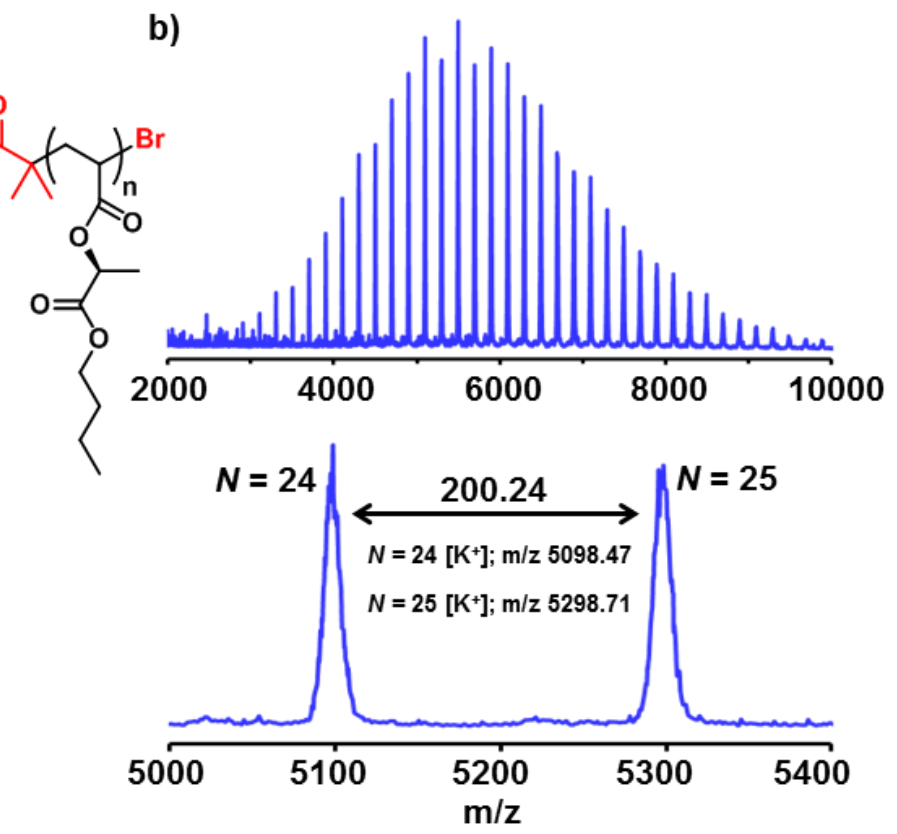

Figure 6. (a) GPC traces (normalized to peak height) for the poly(ELA) synthesized using bisEBiB and $(\mathrm{OH})_{2} \mathrm{EBiB}$ (see entries 3 and 4 in Table 3 for polymerization conditions). Numbers shown in black above GPC traces correspond to monomer conversion, $M_{\mathrm{n}}(\mathrm{GPC})$, and $M_{\mathrm{w}} / M_{\mathrm{n}}$ respectively from the top to bottom. (b) MALDI-TOF spectrum of poly(BLA) synthesized by SET-LRP using $(\mathrm{OH})_{2} \mathrm{EBiB}$ initiator. Magnified region in (b) confirms the expected peak-to-peak spacing for BLA repeating unit and the near perfect bromine chain end functionality of the synthesized polymer.

Table 3. $\mathrm{Cu}(0)$ Wire-Catalyzed SET-LRP of MLA and BLA in EtOH at $25^{\circ} \mathrm{C}$.

\begin{tabular}{|c|c|c|c|c|c|c|c|c|c|}
\hline entry & monomer & initiator & {$[\mathrm{M}]_{0} /[\text { Initiator }]_{0} /\left[\mathrm{Me}_{6}-\mathrm{TREN}\right]_{0}$} & $\begin{array}{c}k_{\mathrm{p}}^{\text {app }} \\
\left(\mathbf{m i n}^{-1}\right)\end{array}$ & $\begin{array}{c}\text { time } \\
\text { (min) }\end{array}$ & $\begin{array}{c}\text { conv. }^{b} \\
(\%)\end{array}$ & $M(t h)^{c}$ & $M_{\mathrm{n}}^{\mathrm{d}}$ & $M_{w} / M_{n}^{\mathrm{d}}$ \\
\hline 1 & MLA & $\mathrm{EBiB}$ & $100 / 1 / 0.1$ & 0.0235 & 80 & 87 & 13,730 & 15,500 & 1.18 \\
\hline 2 & BLA & $\mathrm{EBiB}$ & $50 / 1 / 0.1$ & 0.0254 & 110 & 93 & 9,455 & 10,200 & 1.20 \\
\hline 3 & MLA & bisEBiB & $300 / 1 / 0.5$ & - & 300 & 94 & 44,960 & 47,620 & 1.22 \\
\hline 4 & BLA & $(\mathrm{OH})_{2} \mathrm{EBiB}$ & $30 / 1 / 0.1$ & - & 270 & 93 & 6,120 & 5,000 & 1.25 \\
\hline
\end{tabular}

\footnotetext{
${ }^{\text {a }}$ Polymerization conditions: monomer $=1 \mathrm{~mL}, \mathrm{EtOH}=0.5 \mathrm{~mL}$ (for entries 1,2 and 4 ) and $0.75 \mathrm{~mL}$ (for entry 3 ), $4.5 \mathrm{~cm}$ of hydrazine-activated $\mathrm{Cu}(0)$ wire (20-gauge diameter). ${ }^{\mathbf{b}}$ Determined by ${ }^{1} \mathrm{H}$ NMR. ${ }^{\mathbf{c}} \mathrm{M}($ th $)=\mathrm{MW}$ (monomer) $\mathrm{x}[\mathrm{M}]_{0} /[\text { Initiator }]_{0} \mathrm{x}$ conv $+\mathrm{MW}$ (initiator). ${ }^{\mathrm{d}}$ Determined by GPC using PMMA standards.
} 


\section{Block Copolymerization of poly(ethyl lactate acrylate) with Bio-based $\alpha$-Pinene and Solketal}

Acrylates. Poly(alkyl lactate acrylate)s are amorphous hydrophobic polymers with glass transition temperature $\left(T_{\mathrm{g}}\right)$ below ambient temperature and thermal stability comparable to conventional alkyl acrylates (see discussion in supplementary information, Figure S12a,b). Also appealing is the chiroptical activity of these bio-based polymers (Figure S13 and Table S1). Boosted by the near-perfect retention of bromine chain-ends at high conversion in ethanolic SET-LRP, we investigated the block copolymerization of poly(ELA) by sequential addition of a second vinylic monomer. Two diblock copolymers of ELA were targeted using $\alpha$-pinene acrylate $(\alpha \mathrm{PA}),{ }^{52}$ which is derived from one of the most abundant turpentine components, and the glycerol-derived solketal acrylate (SA) ${ }^{76}$ as a comonomers. Preliminary experiments were conducted to confirm for the first time that well-defined poly $(\alpha \mathrm{PA})$ is also accessible by SET-LRP in $\mathrm{EtOH}$. Despite the polymerization of this bulky and hydrophobic monomer occurred through a selfgenerated biphasic system, ${ }^{59}$ kinetic plots evidenced living character and MALDI-TOF analysis confirmed near-perfect end group fidelity (Figures S14-17). The in situ $\mathrm{Cu}(0)$ wire-catalyzed SET-LRP chainextension of poly(ELA) at high conversion $(>95 \%)$ with equivalent amount of $\alpha \mathrm{PA}(\mathrm{DP}=50)$ and twice as much SA $(\mathrm{DP}=100)$ was successful at synthesizing the corresponding AB block copolymers. In both cases, SEC curve of the first block shifted to lower retention time while retaining narrow MWD after chain extension, thus hinting at successful chain-growing from the $\omega$-bromo terminal of poly(ELA) (Figure 7). Differential scanning calorimetry (DSC) analysis of poly(ELA)- $b$-poly $(\alpha \mathrm{PA})$ reveled the existence of two distinct $T_{\mathrm{g}} \mathrm{s}$ (Figure $8 \mathrm{a}$, red trace). These $T_{\mathrm{g}} \mathrm{s}$ can be ascribed to those of the poly(ELA) and poly $(\alpha \mathrm{PA})$ segments (green and black traces, respectively), suggesting immiscibility between the poly(ELA) segments with the bulky pol( $\alpha \mathrm{PA})$. The existence of microphase separated morphology in this system

could be exploited in the preparation of innovative ABA sustainable thermoplastic elastomers. ${ }^{9,10,11,12}$ Conversely, poly(ELA)- $b$-poly(GA) showed only one $T_{\mathrm{g}}$ at $2{ }^{\circ} \mathrm{C}$ but the hydrolysis of the acetal protecting 
group of SA segments in acidic media afforded a novel block copolymer poly(ELA)-b-poly(GA) (Figure $\mathrm{S} 18){ }^{76,77,78}$
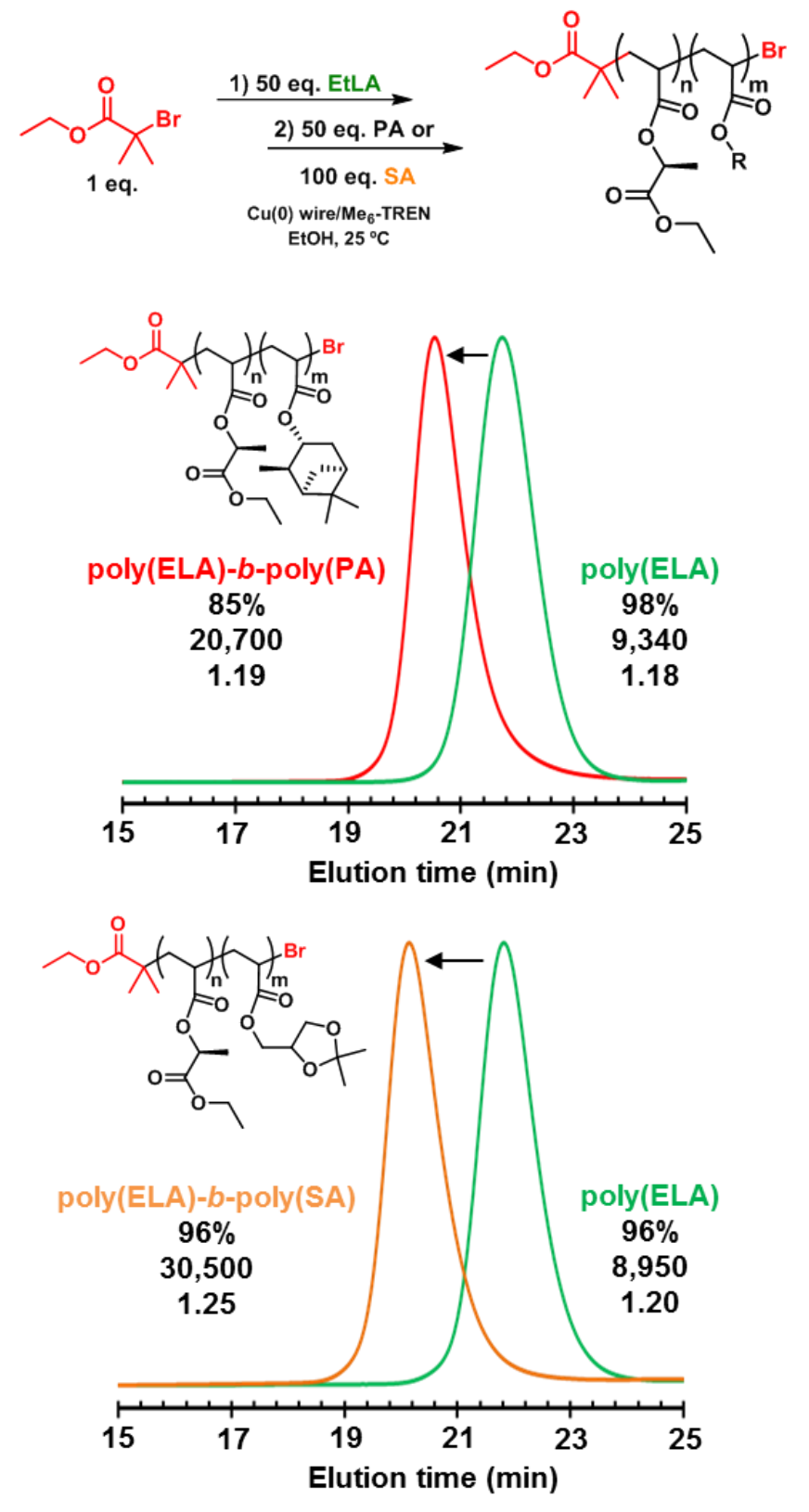

Figure 7. GPC traces for the in situ block copolymerization of ELA with $\alpha \mathrm{PA}$ and SA. Initial conditions for block copolymerization: $[\mathrm{ELA}]_{0} /[\mathrm{EBiB}]_{0} /\left[\mathrm{Me}_{6}-\mathrm{TREN}\right]=50 / 1 / 0.1, \mathrm{ELA}: \mathrm{EtOH}=2: 1(\mathrm{v} / \mathrm{v}), 4.5 \mathrm{~cm}$ of hydrazine-activated $\mathrm{Cu}(0)$ wire (20 gauge). Block copolymerization achieved by addition of a) aPA (50 equiv.) and $\mathrm{Me}_{6}$-TREN (0.1 equiv) in EtOH $(\alpha \mathrm{PA}: \mathrm{EtOH}=2: 1(\mathrm{v} / \mathrm{v}))$ and b) SA (100 equiv.) and $\mathrm{Me}_{6}-$ TREN (0.1 equiv) in EtOH (SA:EtOH = 2:1 (v/v)). 
FTIR-ATR analysis was used to confirm the complete removal of isopropylidene acetal groups and consequently the preparation of a new copolymer which is amphiphilic in nature with poly(GA) as the hydrophilic segment and poly(ELA) being hydrophobic (Figure S19). Stable micellar aggregates in aqueous solution could be simply prepared by nanoprecipitation method. The formation of micelles was first proved by tracking fluorescence intensity of pyrene as a function of the polymer concentration. The change of fluorescence emission intensity of pyrene in poly(ELA)-b-poly(GA) aqueous solutions at different concentrations is depicted in Figure S20. In spite of the constant pyrene concentration, the fluorescence intensity increased and an obvious intensity variation occurred for fluorescence emission peaks at 382 and $372 \mathrm{~nm}$ as the polymer concentration increased from $1.0 \times 10^{-9}$ to $1.0 \times 10^{-3} \mathrm{~g} \mathrm{~L}^{-1}$. This phenomenon was attributed to the formation of micelles in the system and the movement of pyrene probe from the polar aqueous environment into the hydrophobic micelles core where shows much stronger fluorescence. The excitation intensity ratio of $\mathrm{I}_{382} / \mathrm{I}_{372}$ was plotted against the logarithmic concentration $(\log c)$ of copolymer and the concentration corresponding to the intersection of the two tangential lines was considered the critical micelle concentration (CMC) value (Figure 8b). The CMC of poly(ELA)-bpoly(GA) was determined to be $1.3 \mathrm{mg} / \mathrm{L}$, which is comparable with other block copolymers used as drug delivery systems. ${ }^{79,80,81}$ Further, shape and size of the micelles were determined using transmission electron microscopy (TEM) and dynamic light scattering (DLS). As can be seen in Figure 8c, micelles from poly(ELA)-b-poly(GA) displayed spherical morphology. Finally, z-average hydrodynamic diameter $\left(d_{\mathrm{H}}\right)$ of the micelles was determined to be $67 \pm 1.6 \mathrm{~nm}$ (PDI $=0.19$ ) by DLS (Figure 8d). Collectively, these results suggest that that amphiphilic block copolymers with hydrophilic poly(GA) shells and poly(ELA) in the hydrophobic core could potentially be used as hydrophobic drug carriers. ${ }^{82}$ Moreover, due the chiral nature of the lactic acid synthon, other potential applications of poly(ELA)-based 
amphiphilic copolymers could be as enenatioselective sensors or chiral catalysts for asymmetric synthesis..$^{83,84,85,86}$<smiles>CCOC(=O)C(C)OC(=O)C(C)C(=O)OCC</smiles>

poly(ELA) $M_{\mathrm{n}}=34,200$

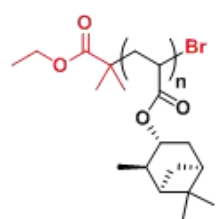

poly(PA)

$M_{\mathrm{n}}=3,900$

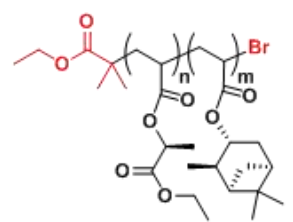

poly(ELA)-b-poly(PA)

$M_{\mathrm{n}}=20,700$

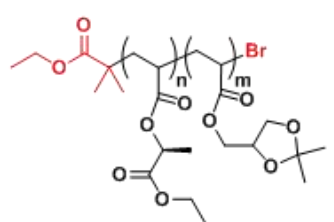

poly (ELA)-b-poly(SA)

$M_{\mathrm{n}}=30,500$

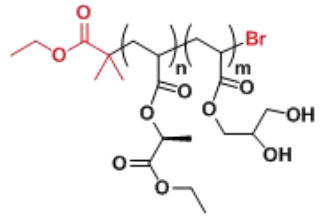

poly(ELA)-b-poly(GA)

$M_{\mathrm{n}}=30,200$
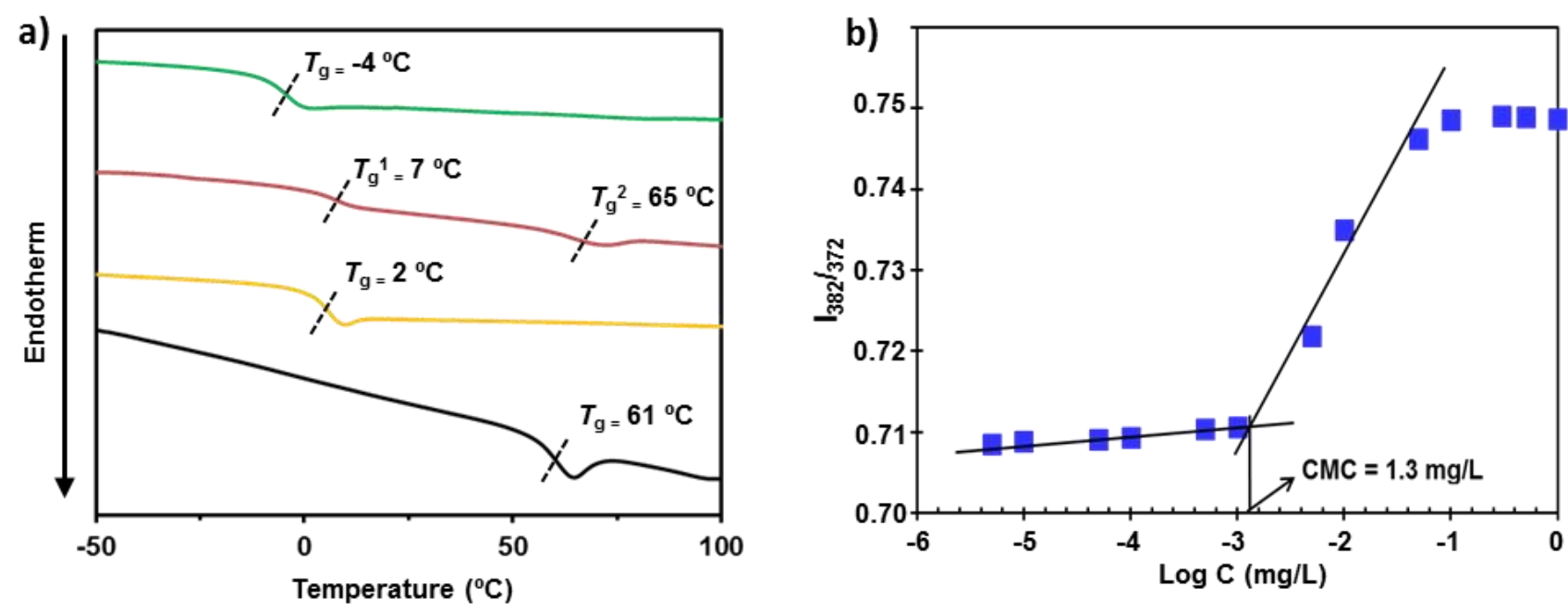

c)

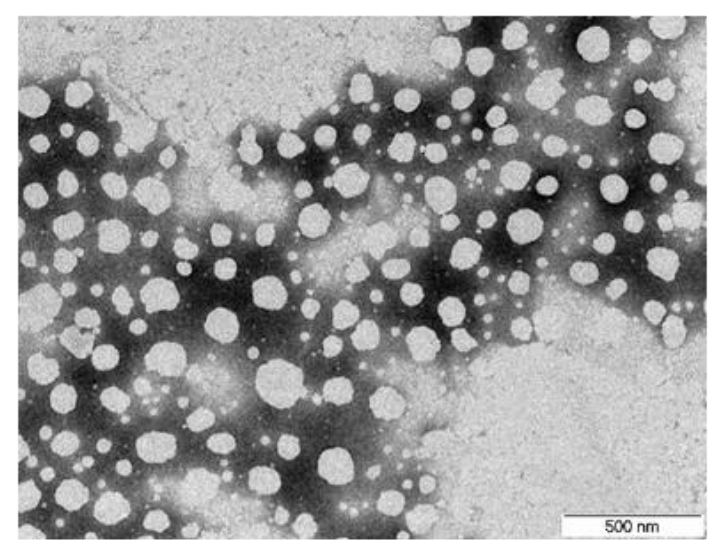

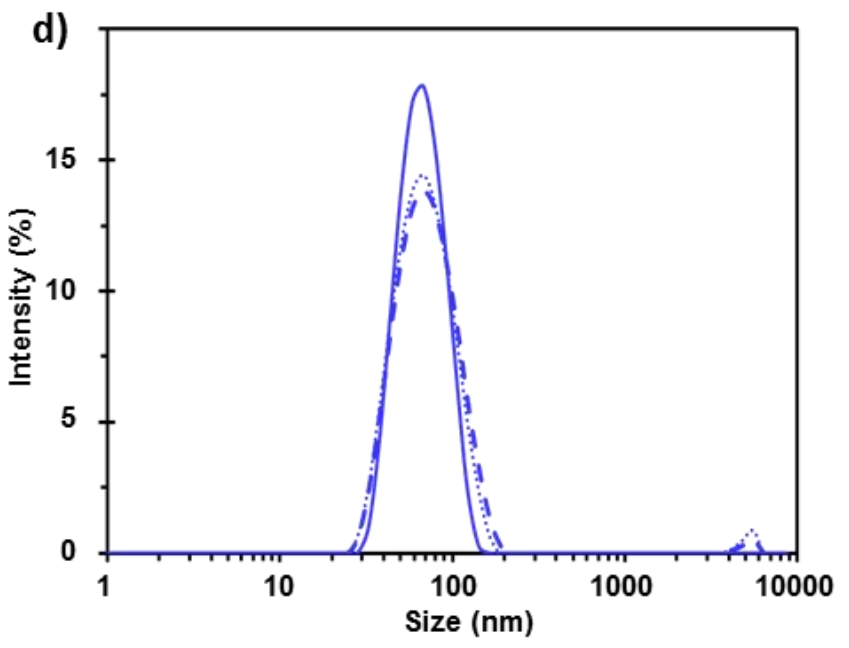

Figure 8. (a) Differential scanning calorimetry (DSC) analysis of various homopolymers and block copolymers obtained by $\mathrm{Cu}(0)$ wire-catalyzed SET-LRP in EtOH. Characterization of poly(ELA)-bpoly(GA) micelles: (b) plot of the fluorescence intensity ratio $\left(\mathrm{I}_{382} / \mathrm{I}_{372}\right)$ for pyrene versus the log of micelle concentration, (c) TEM image and (d) DLS size distribution. 


\section{CONCLUSIONS}

The synthesis of polymers by LRP of alkyl lactate ester acrylates was reported here for the first time. Two different methods were elaborated for the synthesis of the bio-based forgotten acrylate monomers based on ethyl lactate (EL), and of homologous structures based on methyl- and n-butyl- acrylates. Their SETLRP in alcohols, in mixtures of alcohols and water, and in biphasic mixtures of alcohols with water provided excellent control of their molecular weight, polydispersity and chain end functionality that creates the basis for the synthesis of polymers with more complex architecture. A block copolymer of poly(ELA)-b-poly(glycerol acrylate) was shown to form micellar assemblies in water and thus demonstrated that SET-LRP methods for the monomers elaborated here could be used to design and synthesize a large diversity of new complex biomaterials based on these and other bio-based monomers.

\section{ASSOCIATED CONTENT}

Addition polymerization and characterization results including SFC analysis, DSC and TGA traces and ${ }^{1} \mathrm{H}$ NMR spectra (PDF)

\section{AUTHOR INFORMATION}

Corresponding Authors

* Virgil Percec. E-mail: percec@ sas.upenn.edu

* Gerard Lligadas. E-mail: gerard.lligadas@urv.cat

\section{ACKNOWLEDGEMENTS}

Financial support from the National Science Foundation Grants DMR-1066116, DMR-1807127 and the P. Roy Vagelos Chair at the University of Pennsylvania (to V.P.) are gratefully acknowledged. We also 
thank Spanish Ministerio de Ciencia, Innovación y Universidades through project MAT2017-82669-R (to G.L. and J.C.R) and FPI grant BES-2015-072662 (to A.M.), the Serra Hunter Programme of the Government of Catalonia (to G.L.) and University Rovira i Virgili (DL003536 grant to N. B.). We are grateful also to the Engineering and Physical Sciences Research Council (EPSRC: EP/N019784) (to SMH and ORM)for financial support.

\section{References}

(1) Rodrigues, C.; Vandenberghe, L. P. S.; Woiciechowski, A. L.; de Oliveira, J.; Letti, L. A. J.; Soccol,

C. R. Production and Application of Lactic Acid. In Current Developments in Biotechnology and Bioengineering, $1^{\text {st }}$ ed.; Pandey, A.; Negi, S.; Soccol, C. R., Eds.; Elsevier, Academic Press, 2017; p 543556.

(2) Mäki-Arvela, P.; Simakova, I. L.; Salmi, T.; Murzin, D. Y. Production of Lactic Acid/Lactates from Biomass and Their Catalytic Transformations to Commodities. Chem. Rev. 2014, 114, 1909-1971.

(3) Isikgora, F. H.; Becer, C. R. Lignocellulosic Biomass: a Sustainable Platform for the Production of Bio-Based Chemicals and Polymers. Polym. Chem. 2015, 6, 4497-4559.

(4) Zhu, Y.; Romain, C.; Williams, C. K. Sustainable Polymers from Renewable Resources. Nature 2016, $540,354-362$.

(5) Schneiderman, D. H.; Hillmyer, M. A. 50th Anniversary Perspective: There is a Great Future in Sustainable Polymers. Macromolecules 2017, 50, 3733-3749. 
(6) Nagarajan, V.; Mohanty, A. K.; Misra, M. Perspective on Polylactic Acid (PLA) based Sustainable Materials for Durable Applications: Focus on Toughness and Heat Resistance. ACS Sustainable Chem. Eng. 2016, 4, 2899-2916.

(7) Raquez J. M.; Habibi Y.; Murariu M.; Dubois P. Polylactide (PLA)-based nanocomposites. Prog. Polym. Sci. 2013, 38, 1504-1542.

(8) Inkinen, S.; Hakkarainen, M.; Albertsson, A. C.; Södergård, A. From Lactic Acid to Poly(lactic acid) (PLA): Characterization and Analysis of PLA and Its Precursors. Biomacromolecules 2011, 12, 523-532 (9) Ding, W.; Wang, S.; Yao, K.; Ganewatta, M. S.; Tang, C.; Robertson, M. L. Physical Behavior of Triblock Copolymer Thermoplastic Elastomers Containing Sustainable Rosin-Derived Polymethacrylate End Blocks. ACS Sustainable Chem. Eng. 2017, 5, 11470-11480.

(10) Satoh, K.; Lee, D. H.; Nagai, K.; Kamigaito, M. Precision Synthesis of Bio-Based Acrylic Thermoplastic Elastomer by RAFT Polymerization of Itaconic Acid Derivatives. Macromol. Rapid Commun. 2014, 35, 161-167.

(11) Nasiria, M.; Reineke, T. M. Sustainable Glucose-based Block Copolymers Exhibit Elastomeric and Adhesive Behavior. Polym. Chem. 2016, 7, 5233-5240.

(12) Gallagher, J. J.; Hillmyer, M. A.; Reineke, T. M. Acrylic Triblock Copolymers Incorporating Isosorbide for Pressure Sensitive Adhesives. ACS Sustainable Chem. Eng. 2016, 4, 3379-3387.

(13) Percec, V.; Guliashvili, T.; Ladislaw, J. S.; Wistrand, A.; Stjerndahl, A.; Sienkowska, M. J.; Monteiro, M. J.; Sahoo, S. Ultrafast Synthesis of Ultrahigh Molar Mass Polymers by Metal-Catalyzed Living Radical Polymerization of Acrylates, Methacrylates, and Vinyl Chloride Mediated by SET at $25^{\circ} \mathrm{C}$. J. Am. Chem. Soc. 2006, 128, 14156-14165. 
(14) Percec, V.; Popov, A. V.; Ramirez-Castillo, E.; Monteiro, M.; Barboiu, B.; Weichold, O.; Asandei, A. D.; Mitchell, C. M. Aqueous Room Temperature Metal-Catalyzed Radical Polymerization of Vinyl Chloride. J. Am. Chem. Soc. 2002, 124, 4940-4941.

(15) Rosen, B. M.; Percec, V. Single-Electron Transfer and Single-Electron Transfer Degenerative Chain Transfer Living Radical Polymerization. Chem. Rev. 2009, 109, 5069-5119.

(16) Zhang, N.; Samanta, S. R.; Rosen, B. M.; Percec, V. Single Electron Transfer in Radical Ion and Radical-Mediated Organic, Materials and Polymer Synthesis. Chem. Rev. 2014, 114, 5848-5958.

(17) Lligadas, G.; Grama, S.; Percec, V. Single-Electron Transfer Living Radical Polymerization Platform to Practice, Develop and Invent. Biomacromolecules 2017, 18, 2981-3008.

(18) Boyer, C.; Corrigan, N. A.; Jung, K.; Nguyen, D.; Nguyen, T. K.; Adnan, N. N.; Oliver, S.; Shanmugam, S.; Yeow, J. Copper-Mediated Living Radical Polymerization (Atom Transfer Polymerization and Copper(0) Mediated Polymerization): From Fundamentals to Bioapplications. Chem. Rev. 2016, 116, 1803-1949.

(19) Anastasaki, A.; Nikolaou, V.; Nurumbetov, G.; Wilson, O.; Kempe, K.; Quinn, J. F.; Davis, T. P.; Whittaker, M. R.; and Haddleton, D. M. Cu(0)-Mediated Living Radical Polymerization: a Versatile Tool for Materials Synthesis. Chem. Rev. 2016, 116, 835-877.

(20) Nguyen, N. H.; Levere, M. E.; Kulis, J.; Monteiro, M. J.; Percec, V. Analysis of the Cu(0)-Catalyzed Polymerization of Methyl Acrylate in Disproportionating and Nondisproportionating Solvents. Macromolecules 2012, 45, 4606-4622.

(21) Rosen, B. M.; Jiang, X.; Wilson, C. J.; Nguyen, N. H.; Monteiro, M. J.; Percec, V. The Disproportionation of $\mathrm{Cu}(\mathrm{I}) \mathrm{X}$ Mediated by Ligand and Solvent Into $\mathrm{Cu}(0)$ and $\mathrm{Cu}(\mathrm{II}) \mathrm{X}_{2}$ and Its Implications for SET-LRP. J. Polym. Sci., Part A: Polym. Chem. 2009, 47, 5606-5628. 
(22) Levere, M. E.; Nguyen, N. H.; Leng, X.; Percec, V. Visualization of the Crucial Step in SET-LRP. Polym. Chem. 2013, 4, 1635-1647.

(23) Lligadas, G.; Percec, V. Synthesis of Perfectly Bifunctional Polyacrylates by Single-ElectronTransfer Living Radical Polymerization. J. Polym. Sci., Part A: Polym. Chem. 2007, 45, 4684-4695.

(24) Nguyen, N. H.; Lenga, X.; Percec, V. Synthesis of Ultrahigh Molar Mass Poly(2-Hydroxyethyl Methacrylate) by Single-Electron Transfer Living Radical Polymerization. Polym. Chem. 2013, 4, 27602766.

(25) Boyer, C.; Zetterlund, P. B.; Whittaker, M. R. Synthesis of Complex Macromolecules Using Iterative Copper(0)-Mediated Radical Polymerization. J. Polym. Sci., Part A: Polym. Chem. 2014, 52, 2083-2098. (26) Alsubaie, F.; Anastasaki, A.; Wilson, P.; Haddleton, D. M. Sequence-Controlled Multi-Block Copolymerization of Acrylamides via Aqueous SET-LRP at $0{ }^{\circ} \mathrm{C}$. Polym. Chem. 2015, 6, 406-417.

(27) Enayati, M.; Smail, R. B.; Grama, S.; Jezorek, R. L.; Monteiro, M. J.; Percec, V. The Synergistic Effect During Biphasic SET-LRP in Ethanol-Nonpolar Solvent-Water Mixtures. Polym. Chem. 2016, 7 , $7230-7241$.

( 28 ) Enayati, M.; Jezorek, R. L.; Monteiro, M. J.; Percec, V. Ultrafast SET-LRP of Hydrophobic Acrylates in Multiphase Alcohol-Water Mixtures. Polym. Chem. 2016, 7, 3608-3621.

(29) Moreno, A.; Liu, T.; Ding, L.; Buzzacchera, I.; Galià, M.; Möller, M.; Wilson, C. J.; Lligadas, G.; Percec, V. SET-LRP in Biphasic Mixtures of Fluorinated Alcohols with Water. Polym. Chem. 2018, 9, 2313-2327.

( 30 ) Moreno, A.; Galià, M.; Lligadas, G.; Percec, V. SET-LRP in Biphasic Mixtures of the Nondisproportionating Solvent Hexafluoroisopropanol with Water. Biomacromolecules 2018, 19, 44804491. 
(31) Moreno, A.; Jezorek, R. L.; Liu, T.; Galià, M.; Lligadas, G.; Percec, V. Macromonomers, Telechelics and More Complex Architectures of PMA by a Combination of Biphasic SET-LRP and Biphasic Esterification. Polym Chem. 2018, 9, 1885-1899.

(32) Moreno, A.; Liu, T.; Galià, M.; Lligadas, G.; Percec, V. Acrylate-macromonomers and Telechelics of PBA by Merging Biphasic SET-LRP of BA, Chain Extension with MA and Biphasic Esterification. Polym Chem. 2018, 9, 1961-1971.

(33) Grama, S.; Lejnieks, J.; Enayati, M.; Smail, R. B.; Ding, L.; Lligadas, G.; Monteiro M. J.; Percec, V. Searching for Efficient SET-LRP Systems via Biphasic Mixtures of Water with Carbonates, Ethers and Dipolar Aprotic Solvents. Polym. Chem. 2017, 8, 5865-5874.

(34) Zhang, Q.; Wilson, P.; Anastasaki, A.; McHale, R.; Haddleton, D. M. Synthesis and Aggregation of Double Hydrophilic Diblock Glycopolymers via Aqueous SET-LRP. ACS Macro. Lett. 2014, 3, 491-495. (35) Zhang, Q.; Collins, J.; Anastasaki, A.; Wallis, R.; Mitchell, D. A.; Becer, C. R.; Haddleton, D. M. Sequence-Controlled Multi-Block Glycopolymers to Inhibit DC-SIGN-gp120 Binding. Angew. Chem. Int. Ed. 2013, 52, 4435-4439.

(36 ) Voepel, J.; Edlund, U.; Albertsson, A. C.; Percec, V. Hemicellulose-Based Multifunctional Macroinitiator from Single-Electron-Transfer Mediated Living Radical Polymerization. Biomacromolecules 2011, 12, 253-259.

(37) Edlund, U.; Albertsson, A. C. SET-LRP Goes “Green": Various Hemicellulose Initiating Systems under Non-Inert Conditions. J. Polym. Sci., Part A: Polym. Chem. 2012, 50, 2650-2658.

(38) Shibaeva, O.; Champagne, P.; Cunningham, M. F. Green Solvents Systems for Copper WireMediated Living Radical Polymerization. Green Meter. 2016, 2, 104-114.

(39) Ma, J.; Chen, H.; Zhang, M; Yu, M. SET-LRP of Acrylonitrile in Ionic Liquids without any Ligand. J. Polym. Sci., Part A: Polym. Chem. 2012, 50, 609-613. 
(40) Bertrand, O.; Wilson, P.; Burns, J. A.; Bell, G. A.; Haddleton, D. M. Cu(0)-Mediated Living Radical Polymerisation in Dimethyl Lactamide (DML); an Unusual Green Solvent with Limited Environmental Impact. Polym. Chem. 2015, 6, 8319-8324.

(41) Moreno, A.; Garcia, D.; Galià, M.; Ronda, J. C.; Cádiz, V.; Lligadas, G.; Percec, V. SET-LRP in the Neoteric Ethyl Lactate Alcohol. Biomacromolecules 2017, 18, 3447-3456.

(42) Pereira, C. S. M.; Silva, V. M. T. M.; Rodrigues, A. E. Ethyl Lactate as a Solvent: Properties, Applications and Production Processes - a Review. Green Chem. 2011, 13, 2658-2671.

(43) Paul, S.; Pradhan, K.; Das, A. R. Ethyl Lactate as a Green Solvent: a Promising Bio-compatible Media for Organic Synthesis. Curr. Org. Chem. 2016, 3, 111-118.

(44) Jessop, P. G. Searching for Green Solvents. Green Chem. 2011, 13, 1391-1398

(45) Gu, Y.; Jérôme, F. Bio-based Solvents: and Emerging Generation of Fluids for the Design of EcoEfficient Processes in Catalysis and Organic Chemistry. Chem. Soc. Rev. 2013, 42, 9550-9770.

(46) Purushothaman, M., Krishnan, P. S. G. \& Nayak, S. K. Poly(alkyl lactate acrylate)s Having Tunable Hydrophilicity. J. Appl. Polym. Sci. 2014, 131, 40962.

(47) Purushothaman, M., Krishnan, P. S. G. \& Nayak, S. K. Tunable Hydrophilicity of Poly(ethyl lactate acrylate-co-acrylic acid). J. Renew. Mater. 2015, 3, 292-301.

(48) Purushothaman, M., Krishnan, P. S. G. \& Nayak, S. K. Effect of Isoalkyl Lactates as Pendant Group on Poly(acrylic acid). J. Macromol. Sci. A. 2014, 51, 470-480.

(49) Kavitha, A. A.; Singha, N. K. Smart “All Acrylate” ABA Triblock Copolymer Bearing Reactive Functionality via Atom Transfer Radical Polymerization (ATRP): Demonstration of a "Click Reaction" in Thermoreversible Property. Macromolecules 2010, 43, 3193-3205.

(50) Gavrilov, M.; Zerk, T. J.; Bernhardt, P. V.; Percec, V.; Monteiro, M. J. SET-LRP of NIPAM in Water via in situ Reduction of $\mathrm{Cu}(\mathrm{II})$ to $\mathrm{Cu}(0)$ with $\mathrm{NaBH}_{4}$. Polym. Chem. 2016, 7, 933-939. 
(51) Oguchi, K.; Sanui, K.; Ogata, N.; Takahashi, Y.; Nakada, T. Relationship Between Electron Sensitivity and Chemical Structures of Polymers as Electron Beam Resist. VII: Electron Sensitivity of Vinyl Polymers Containing Pendant 1,3-Dioxolan Groups. Polym. Eng. Sci. 1990, 30, 449-452.

(52) Sainz, M. F.; Souto, J. A.; Regentova, D.; Johansson, M. K. G.; Timhagen, S. T.; Irvine, D. J.; Buijsen, P.; Koning, C. E.; Stockman, R. A.; Howdle, S. M. A Facile and Green Route to Terpene Derived Acrylate and Methacrylate Monomers and Simple Free Radical Polymerisation to Yield New Renewable Polymers and Coatings. Polym. Chem. 2016, 7, 2882-2887.

(53) Enayati, M.; Jezorek, R. L and Percec, V. A Multiple-stage Activation of the Catalytically Inhomogeneous $\mathrm{Cu}(0)$ Wire Used in SET-LRP. Polym. Chem. 2016, 7, 4549-4558.

(54) Waghmare, A. A.; Hindupur, R. M.; Pati, H. N. Propylphosphonic Anhydride (T3P®): An Expedient Reagent for Organic Synthesis. Rev. J. Chem. 2014, 4, 53-131.

(55) Levere, M. E.; Nguyen, N. H.; Sun, H. J.; Percec, V. Interrupted SET-LRP of Methyl Acrylate Demonstrates $\mathrm{Cu}(0)$ Colloidal Particles as Activating Species. Polym. Chem. 2013, 4, 686-694.

(56) Nguyen, N. H.; Rosen, B. M.; Percec, V. Improving the Initiation Efficiency in the Single Electron Transfer Living Radical Polymerization of Methyl Acrylate with Electronic Chain-End Mimics. J. Polym. Sci., Part A: Polym. Chem. 2011, 49, 1235-1247.

(57) Nguyen, N. H.; Percec, V. SET-LRP of Methyl Acrylate Catalyzed with Activated Cu(0) Wire in Methanol in the Presence of Air. J. Polym. Sci., Part A: Polym. Chem. 2011, 49, 4756-4765.

(58) Nguyen, N. H.; Rosen, B. M.; Percec, V. SET-LRP of N,N,-Dimethylacrylamide and of NIsopropylacrylamide at $25^{\circ} \mathrm{C}$ in Protic and in Dipolar Aprotic Solvents. J. Polym. Sci., Part A: Polym. Chem. 2010, 48, 1752-1763. 
(59) Boyer, C.; Atme, A.; Waldron, C.; Anastasaki, A.; Wilson, P.; Zetterlund, P. B.; Haddleton, D. M.;

Whittaker, M. R. Copper(0)-Mediated Radical Polymerization in a Self-Generating Biphasic System. Polym. Chem. 2013, 4, 106-112.

(60) Lligadas, G.; Percec, V. Ultrafast SET-LRP of Methyl Acrylate at $25{ }^{\circ} \mathrm{C}$ in Alcohols. J. Polym. Sci., Part A: Polym. Chem. 2008, 46, 2745-2754.

(61) Samanta, S. R.; Cai, R.; Percec, V. SET-LRP of Semifluorinated Acrylates and Methacrylates. Polym. Chem. 2014, 5, 5479-5491.

(62) Samanta, S. R.; Levere, M. E.; Percec, V. SET-LRP of Hydophobic and Hydrophilic Acrylates in Trifluoroethanol. Polym. Chem. 2013, 4, 3212-3224.

(63) Bensabeh, N.; Ronda, J. C.; Galià, M.; Cádiz, V.; Lligadas, G.; Percec, V. SET-LRP of the Hydrophobic Biobased Menthyl Acrylate. Biomacromolecules 2018, 19, 1256-1268.

(64) Rosen, B. M., Lligadas, G., Hahn, C. and Percec, V. Synthesis of Dendrimers Through Divergent Iterative Thio-Bromo “Click” Chemistry. J. Polym. Sci., Part A: Polym. Chem. 2009, 47, 3931-3939.

(65) Rosen, B. M.; Lligadas, G.; Hahn, C.; Percec, V. Synthesis of Dendritic Macromolecules Through Divergent Iterative Thio-Bromo "Click" Chemistry and SET-LRP. J. Polym. Sci., Part A: Polym. Chem. 2009, 47, 3940-3948.

(66) Nguyen, N. H. and Percec, V. Disproportionating versus Nondisproportionating Solvent Effect in the SET-LRP of Methyl Acrylate During Catalysis with Nonactivated and Activated Cu(0) wire. J. Polym. Sci., Part A: Polym. Chem. 2011, 49, 4227-4240.

(67) Nguyen, N. H.; Rosen, B. M.; Jiang, X.; Fleischmann, S.; Percec, V. New Efficient Reaction Media for SET-LRP Produced from Binary Mixtures of Organic Solvents and $\mathrm{H}_{2} \mathrm{O}$. J. Polym. Sci., Part A: Polym. Chem. 2009, 47, 5577-5590. 
(68) Jiang, X.; Fleischmann, S.; Nguyen, N. H.; Rosen, B. M.; Percec, V. Cooperative and Synergistic Solvent Effects in SET-LRP of MA. J. Polym. Sci., Part A: Polym. Chem. 2009, 47, 5591-5605.

(69) Nguyen, N. H.; Levere, M. E.; Kulis, J.; Monteiro, M. J.; Percec, V. Analysis of the Cu(0)-Catalyzed Polymerization of Methyl Acrylate in Disproportionating and Nondisproportionating Solvents. Macromolecules 2012, 45, 4606-4622.

(70) Lligadas, G. and Percec, V. A Comparative Analysis of SET-LRP of MA in Solvents Mediating Different Degrees of Disproportionation of Cu(I)Br. J. Polym. Sci., Part A: Polym. Chem. 2008, 46, 6880-6895.

(71) Lligadas, G.; Rosen B. M.; Monteiro, M. J.; Percec V. Solvent Choice Differentiates SET-LRP and Cu-Mediated Radical Polymerization with Non-First-Order Kinetics. Macromolecules 2008, 41, 83608364.

(72) Zhang, M.; Fu, Q. Y.; Gao, G.; He, H. Y.; Zhang, Y.; Wu, Y. S.; Zhang, Z. H. Catalyst-Free, VisibleLight Promoted One-Pot Synthesis of Spirooxindole-Pyran Derivatives in Aqueous Ethyl Lactate. ACS Sustainable Chem. Eng. 2017, 5, 6175-6182.

(73) Bennett, J. S.; Charles, K. L.; Miner, M. R.; Heuberger, C. F.; Spina, E. J.; Bartelsa, M. F.; Foremana, T. Ethyl lactate as a Tunable Solvent for the Synthesis of Aryl Aldimines. Green Chem., 2009, 11, 166168.

(74) Ahrland, S.; Rawsthorne, The Stability of Metal Halide Complexes in Aqueous Solution. VII. The Chloride Complexes of Copper(I). J. Acta Chem. Scand. 1970, 24, 157-172.

(75) Ciavatta, L.; Ferri, D.; Palombari, R. On the Equilibrium $\mathrm{Cu}^{2+}+\mathrm{Cu}(\mathrm{s}) \rightleftarrows 2 \mathrm{Cu}^{+}$. J. Inorg. Nucl. Chem. 1980, 42, 593-598.

(76) Pham, P. D.; Monge, S.; Lapinte, V.; Raoul, Y.; Robin, J. J. Various Radical Polymerizations of Glycerol-based Monomers. Eur. J. Lipid Sci. Technol. 2013, 115, 28-40. 
(77) Whittaker, M. R.; Urbani, C. N.; Monteiro, M. J. Synthesis of Linear and 4-Arm Star Block Copolymers of Poly(Methyl Acrylate-b-Solketal Acrylate) by SET-LRP at $25^{\circ} \mathrm{C}$. J. Polym. Sci., Part A: Polym. Chem. 2008, 46, 6346-6357.

(78) Anastasaki, A.; Nikolaou, V.; Simula, A.; Godfrey, J.; Li, M.; Nurumbetov, G.; Wilson, P.; Haddleton, D. M. Expanding the Scope of the Photoinduced Living Radical Polymerization of Acrylates in the Presence of $\mathrm{CuBr}_{2}$ and $\mathrm{Me}_{6}$-Tren. Macromolecules 2014, 47, 3852-3859.

(79) Danafar, H.; Rostamizadeh, K.; Davaran, S.; Hamidi, M. Drug-Conjugated PLA-PEG-PLA Copolymers: a Novel Approach for Controlled Delivery of Hydrophilic Drugs by Micelle Formation. Pharm. Dev. Technol. 2017, 22, 947-957.

(80) Li, F.; Danquah, M.; Mahato, R. I. Synthesis and Characterization of Amphiphilic Lipopolymers for Micellar Drug Delivery. Biomacromolecules 2010, 11, 2610-2620.

(81) Yan, L.; Miller, J.; Yuan, M.; Liu, J. F.; Busch, T. M.; Tsourkas, A.; Cheng, Z. Improved Photodynamic Therapy Efficacy of Protoporphyrin IX-Loaded Polymeric Micelles Using Erlotinib Pretreatment. Biomacromolecules 2017, 18, 1836-1844.

(82) Bodratti, A.M,; Alexandridis P. Amphiphilic Block Copolymers in Drug Delivery: Advances in Formulation Structure and Performance. Expert Opin. Drug Deliv. 2018, 15, 1085-1104.

(83) Skey, J.; O’Reilly, R. K. Synthesis of Chiral Micelles and Nanoparticles from Amino Acid Based Monomers Using RAFT Polymerization. J. Polym. Sci., Part A: Polym. Chem. 2008, 46, 3960-3702.

(84) La Sorella, G.; Strukul, G.; Scarso, A. Recent Advances in Catalysis in Micellar Media. Green Chem. 2015, 17, 644-683.

(85) Ladmiral, V.; Charlot, A.; Semsarilar, M.; Armes, S. P. Synthesis and Characterization of Poly(amino acid methacrylate)-stabilized Diblock Copolymer Nano-objects. Polym. Chem. 2015, 6, 1805-1816. 
(86) Bloksma, M. M.; Hoeppener, S.; D'Haese, C.; Kempe, K.; Mansfeld, U.; Paulus, R. M.; Gohy, J. F.;

Schubert, U. S.; Hoogenboom, R. Self-assembly of Chiral Block and Gradient Copolymers. Soft Matter, 2012, $8,165-172$.

\section{Table of Contents Graphic}

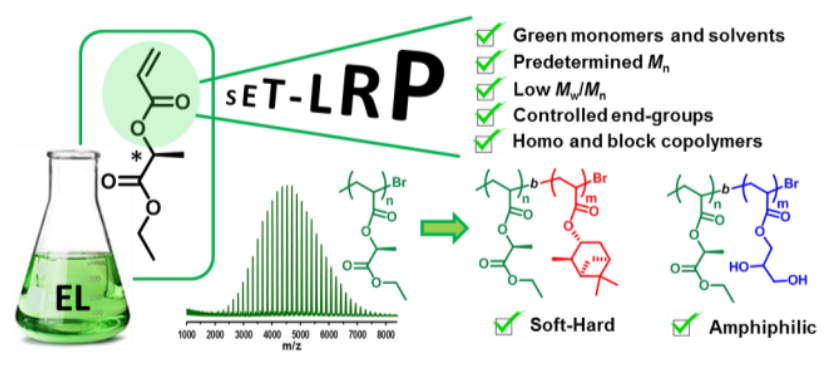

